\title{
Experimental Study on the Effects of Stress Variations on the Permeability of Feldspar-Quartz Sandstone
}

\author{
Fugang Wang, ${ }^{1}$ Zhaoxu Mi, ${ }^{1}$ Zhaojun Sun, ${ }^{1}$ Xufeng Li, ${ }^{2,3}$ Tianshan Lan, \\ Yilong Yuan, ${ }^{1}$ and Tianfu $\mathrm{Xu}^{1}$ \\ ${ }^{1}$ Key Laboratory of Groundwater Resources and Environment, Ministry of Education, Jilin University, Changchun 130012, China \\ ${ }^{2}$ Center for Hydrogeology and Environmental Geology Survey, China Geological Survey, Baoding 071000, China \\ ${ }^{3}$ Key Laboratory of Carbon Dioxide Geological Storage, Center for Hydrogeology and Environmental Geology Survey, \\ China Geological Survey, Baoding 071000, China
}

Correspondence should be addressed to Fugang Wang; wangfugang@jlu.edu.cn

Received 20 February 2017; Revised 24 June 2017; Accepted 9 August 2017; Published 10 September 2017

Academic Editor: Kundan Kumar

Copyright (C) 2017 Fugang Wang et al. This is an open access article distributed under the Creative Commons Attribution License, which permits unrestricted use, distribution, and reproduction in any medium, provided the original work is properly cited.

\begin{abstract}
The multistage and discontinuous nature of the injection process used in the geological storage of $\mathrm{CO}_{2}$ causes reservoirs to experience repeated loading and unloading. The reservoir permeability changes caused by this phenomenon directly impact the $\mathrm{CO}_{2}$ injection process and the process of $\mathrm{CO}_{2}$ migration in the reservoirs. Through laboratory experiments, variations in the permeability of sandstone in the Liujiagou formation of the Ordos $\mathrm{CO}_{2}$ capture and storage (CCS) demonstration project were analyzed using cyclic variations in injection pressure and confining pressure and multistage loading and unloading. The variation in the micropore structure and its influence on the permeability were analyzed based on micropore structure tests. In addition, the effects of multiple stress changes on the permeability of the same type of rock with different clay minerals content were also analyzed. More attention should be devoted to the influence of pressure variations on permeability in evaluations of storage potential and studies of $\mathrm{CO}_{2}$ migration in reservoirs in CCS engineering.
\end{abstract}

\section{Introduction}

Global warming presents a serious threat to the living environment of humans. Reducing the emissions of carbon dioxide $\left(\mathrm{CO}_{2}\right)$ is a common challenge for countries worldwide. The technology of geological storage of $\mathrm{CO}_{2}$ has attracted the attention of governments and scientists around the world as a direct and effective emission reduction technology recognized by the international community [1]. The China Geological Survey and the China Shenhua Group jointly launched a demonstration project of carbon dioxide geological storage in the Ordos Basin in 2010, and the Liujiagou formation is one of the target reservoirs. During the injection process, the reservoir will experience radial stress accumulations surrounding the injection well. In addition, the horizontal stress accumulation during this process will be greater near the injection well. The horizontal radial stress accumulation and injection pressure have obvious effects on the migration and injection of $\mathrm{CO}_{2}$ in the reservoir.
The multistage and discontinuous nature of $\mathrm{CO}_{2}$ injection causes the stress and injection pressure in the reservoirs to repeatedly increase and decrease. The micropore structure of the reservoir may change when reservoir stress field is disrupted. The permeability and other important physical properties of the reservoir may change in response [2, 3]. The variations in permeability during repeated reservoir stress changes, combined with changes in the pore structure characteristics, have great significance for the evaluation of the geological storage of $\mathrm{CO}_{2}$, particularly the capacity, storage potential, and safety of the reservoirs used.

Numerous experimental and theoretical studies have focused on the relationship between stress variations and the permeability of low-permeability rocks in geotechnical engineering, hydraulic engineering, oil and gas reservoir development engineering, and other disciplines [4, 5]. Fatt et al. $[6,7]$ studied the effects of overburden pressure and confining pressure on sandstone permeability. The permeability and overburden pressure are negatively correlated, 
TABLE 1: Mineralogical compositions of the samples (\%).

\begin{tabular}{lccccccc}
\hline Sample & Quartz & Plagioclase & K-feldspar & Calcite & Biotite & Kaolinite & Illite/smectite \\
\hline S1 & 16 & 46 & 29 & 42 & 7 & 3 & 2 \\
S2 & 10 & 12 & & 4 & 5 & 20 \\
\hline
\end{tabular}

as is the relationship between permeability and confining pressure. In addition, the change in the low-pressure zone is more obvious. Wu et al. [8] conducted an experimental study on the impact of pore pressure on permeability using three halite rocks with different compositions. The results show that permeability increases with increasing pore pressure and is influenced by the Klinkenberg effect. Wang et al. [9] used triaxial permeability tests while controlling the axial strain and found that the permeability of marble decreases as the difference between axial pressure and confining pressure increases. Vairogs et al. [10] and Xue et al. [11] suggested that changes in the effective stress affect the pore structure and skeletal structure of rocks, which affect the permeability of the rock. Peng et al. [12] argued that the permeability changes that occur during the elastic stage, the elastic-plastic stage, and the residual flow stage are different because of the differing degrees of rock deformation during the stressstrain process. Additionally, Jennings et al. [13], Peng et al. [12], and Wang et al. [14] constructed different mathematical models of permeability and confining pressure, including a cubic polynomial function, a logarithmic function, a power function, and other single-function mathematical models. Lan et al. [15] proposed a stress sensitivity coefficient model based on the analysis of stress sensitivity data obtained from samples of low-permeability sandstone from oil and gas reservoirs in the Sichuan Basin and Songliao Basin. In addition, they found that the greater the stress sensitivity coefficient, the stronger the reservoir stress sensitivity.

In the literature, there are lots of experiments and theoretical studies whose primary goal was to investigate the permeability stress sensitivity of low-permeability rocks. Additionally, the relationship between stress and permeability has been analyzed under the corresponding conditions. A variety of models that describe the relationship between stress and permeability have been constructed [16]. However, the constructed mathematical models do not have universal applicability, because the study objects differ in terms of rock type, mineral composition, and geochemical properties [17]. The correlation between rock permeability and pore structure is significant for a specific rock formation [2]. The influence of multiphase stress changes on the micropore structure of rock will lead to changes in rock permeability. However, studies of the relationship between the permeability and stress variation based on changes in the micropore structure of rocks are still rarely reported. In addition, the influence of the intermittent pressure dissipation that occurs during the $\mathrm{CO}_{2}$ injection process on permeability has not received much attention from researchers. In a CCS project, the $\mathrm{CO}_{2}$ injection process has a multistage and discontinuous nature due to equipment maintenance and other unforeseen events. Therefore, it is necessary to determine the influence of injection intervals on the recovery of permeability.
In this paper, a $\mathrm{CO}_{2}$ reservoir formation, the Liujiagou formation, part of the Ordos CCS demonstration project in China, was selected as the focus of this study. Based on the specific operation conditions of the CCS project and the environmental characteristics of $\mathrm{CO}_{2}$ reservoirs, the permeability changes in the target reservoir were analyzed under two types of conditions. One condition involved a fixed injection pressure and a variable confining pressure, and the other involved a fixed confining pressure and a variable injection pressure. Quantitative mathematical models of the effects of the confining pressure and injection pressure on the permeability of the rocks in the Liujiagou formation were constructed. The permeability changes have been analyzed, combining the changes in rock micropore structure before and after multiple stages of stress changes. The research results are helpful for numerical simulations and engineering practice in the geological storage of $\mathrm{CO}_{2}$ at the Ordos CCS demonstration project.

\section{Materials and Methods}

2.1. Materials. The Ordos Basin is in the eastern part of Northwest China, and it has a total area of $28.2 \times 10^{4} \mathrm{~km}^{2}$. The basin is rich in coal, oil, natural gas, and mineral resources, such as gypsum. It represents the new energy chemical industry base of China. The Ordos CCS demonstration project, the first CCS project in China, is located in the northeastern portion of the basin. The strata involved range in age from the Paleozoic to the Cenozoic, and their total thickness exceeds $5000 \mathrm{~m}$. According to the engineering design, the Mesozoic (Triassic) Liujiagou formation and the underlying Paleozoic (Permian) strata are the target $\mathrm{CO}_{2}$ storage formations, and these units consist mainly of interbedded sandstone and mudstone [18].

The Liujiagou formation is one of the important $\mathrm{CO}_{2}$ reservoirs of the Ordos CCS demonstration project. The reservoir formation consists of low-permeability sandstone. It is present at a depth of $1576-1699 \mathrm{~m}$ and has a thickness of $123 \mathrm{~m}$ [19]. The porosity is $6.3 \% \sim 13 \%$, the permeability is $0.040 \sim 0.408 \mathrm{mD}$ [3], the formation pressure range is $15.76 \sim$ $16.99 \mathrm{MPa}$ [20], and the formation temperature is $52.74 \sim$ $56.03^{\circ} \mathrm{C}[21]$.

The sandstone rock samples from the Liujiagou formation used in this study are labeled S1 and S2, respectively (Figure 1). Sample S1 has a diameter of $3.792 \mathrm{~cm}$, a length of $7.709 \mathrm{~cm}$, and a porosity of $11.86 \%$. Sample S2 has a diameter of $3.793 \mathrm{~cm}$, a length of $7.482 \mathrm{~cm}$, and a porosity of $11.87 \%$. Both samples are feldspar-quartz sandstones and have similar porosity. However, the clay mineral content is approximately five times higher in S2 than in S1 (Table 1).

2.2. Equipment and Instruments. The experimental instrument used for the permeability tests is an HXKS-A high 


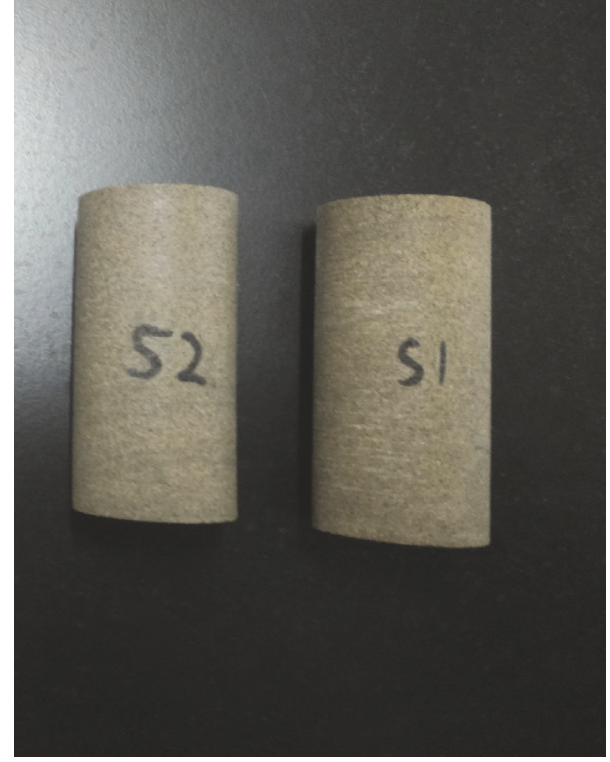

FIgURE 1: Rock samples.

temperature and high-pressure pore fluid displacement test system. The system can be used to measure the permeability of rocks under different pressure conditions, and it can work stably for a long time (30 days) under set temperature and pressure conditions. The system consists of a pressure control system, a temperature control system, and a parameter measurement and control system. The outlet pressure and the confining pressure loading systems are controlled by two constant-speed, constant-pressure, single-cylinder pumps (ISCO-65D). The injection pressure loading system is controlled by a two-cylinder, constant-speed, constantpressure pump (ISCO-100DX). These pumps work within a range of flow rates of $0.0001-45 \mathrm{~mL} / \mathrm{min}$, they have a maximum output pressure of $70 \mathrm{MPa}$, and the pressure is within $0.5 \%$ of the set pressure within 48 hours after a new pressure is selected.

The microscopic pore structure of the rock samples was tested using a 3H-2000PS1 specific surface area and pore size analyzer that was manufactured by Beijing Beishide Instrument Technology Corporation, Limited. The principle of this instrument uses the static volumetric method of isothermal physical adsorption. The adsorption isotherm is measured at $77 \mathrm{~K}$ (the temperature of liquid nitrogen), high-purity nitrogen acts as the adsorption medium, and the relative pressure used is $0.01 \sim 1.00$. The range of pore diameters tested is $0.35 \sim 100.00 \mathrm{~nm}$. The lowest measurable specific surface area is $0.005 \mathrm{~m}^{2} / \mathrm{g}$. The minimum detection volume is $0.0001 \mathrm{~cm}^{3} / \mathrm{g}$. The gas adsorption method can effectively reflect the distribution of nanopores in materials, and it has been widely used in assessing the porous structure of porous materials [22]. Changes in the permeability can be determined by testing the microscopic pore structure of rock samples before and after stress changes.

2.3. Experimental Method. The experimental procedure is shown below.

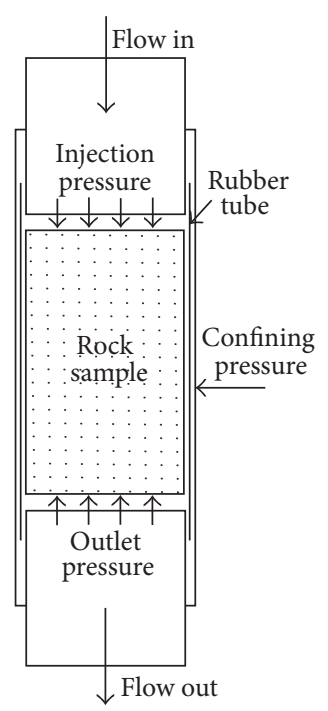

FIGURE 2: Schematic diagram of permeability tests.

(1) The rock samples were processed into cylindrical cores. The lithology and mineral compositions of the rock samples were assessed using X-ray diffractometry.

(2) Some rock samples were taken for use in nitrogen adsorption experiments to ascertain the micropore structure. To eliminate the irreducible water and the capillary water in the samples, the samples were pretreated at $300^{\circ} \mathrm{C}$ for $3 \mathrm{~h}$ under high vacuum before the experiment. The nitrogen adsorption and desorption isotherms of different partial pressures were then measured at $77 \mathrm{~K}$ using high-purity nitrogen as the adsorbent to determine the microscopic pore structure of the rock samples.

(3) The rock samples used to study stress-induced permeability changes were measured in terms of their lengths, diameters, and weights. After the samples were dried in a drying oven for 24 hours, the samples were put into a vacuum saturation bin and saturated with distilled water. The fully saturated cores were then placed in a core holder at a set temperature of $25^{\circ} \mathrm{C}$ to begin the permeability testing under different stress conditions (Figure 2).

(4) As the injection pressure changed, the confining pressure was held constant at $20 \mathrm{MPa}$. The distilled water was injected into the rock samples. The saturated permeability against water of the rock was measured under different injection pressures, starting from the initial pressure of $4 \mathrm{MPa}$ and increasing to the maximum injection pressure of $18 \mathrm{MPa}$ with a pressure increment of $2 \mathrm{MPa}$ (the maximum pressure was less than the rock cracking pressure of $24.84 \mathrm{MPa}$ ). When the permeability experiment reached a steady state at a given injection pressure, the injection pressure was increased to the next injection pressure, according to the pressure increment, until the maximum injection pressure $(18 \mathrm{MPa})$ was reached. In addition, the injection pressure was then unloaded at a pressure increment of $2 \mathrm{MPa}$ until the initial pressure of $4 \mathrm{MPa}$ was reached. The rock permeability was also measured at each pressure during the unloading process. The injection pressure loading and unloading process was repeated 3 times, 

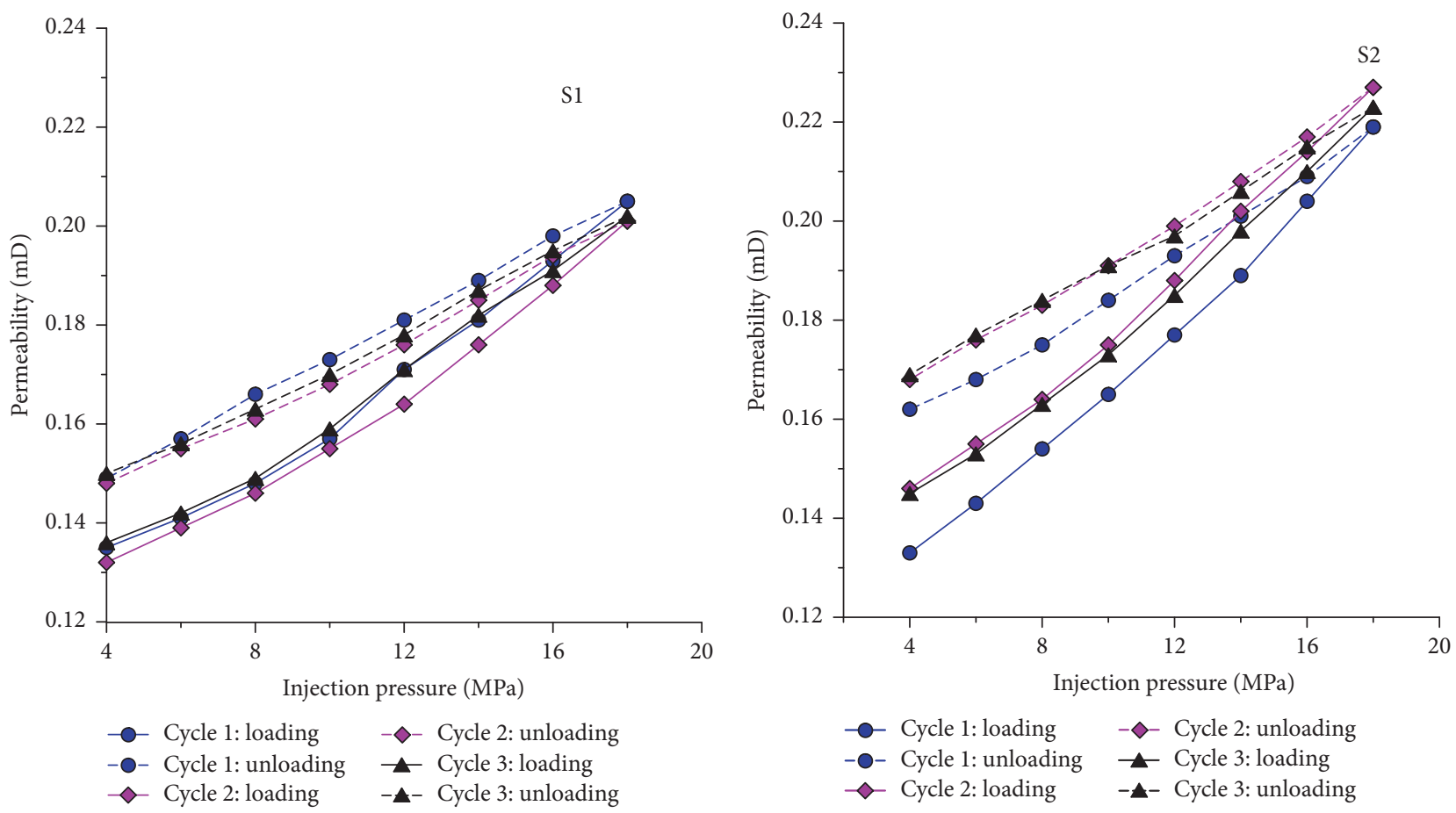

FIGURE 3: Relationship between permeability and injection pressure under constant confining pressure.

and the cycles were labeled Cycle 1, Cycle 2, and Cycle 3 , respectively. The time interval between pairs of adjacent cycles was 24 hours. In addition, during these intervals, the pressure was released, and the experimental sample was removed from the core holder and stored immersed in distilled water.

(5) Under the variable confining pressure, the injection pressure was held constant at $4 \mathrm{MPa}$. The saturated permeability against water of the samples was measured under different confining pressures, starting at an initial pressure of $6 \mathrm{MPa}$ and increasing to the maximum confining pressure of $20 \mathrm{MPa}$ with a pressure increment of $2 \mathrm{MPa}$. The confining pressure loading and unloading process was repeated 3 times. The time interval between pairs of adjacent cycles was 24 hours. During these intervals, the pressure was released and the experimental sample was removed from the core holder and stored immersed in distilled water.

(6) Finally, the microscopic pore structure of the rock samples was tested again after all the permeability experiments under different stress conditions had been completed.

\section{Results and Analysis}

\subsection{Influence of Changing Injection Pressure on Permeability}

3.1.1. Variation in Permeability under Changing Injection Pressure. Figure 3 shows the changes in rock permeability with changing injection pressure in the three cycles of increasing and decreasing injection pressure under constant confining pressure.

The following observations can be made.
(1) Figure 3 shows that the rock permeability increases as the injection pressure increases and that a positive correlation exists between them. With decreasing injection pressure, the permeability of the rock gradually recovers, but the sample does not achieve the same permeability as it had at the same injection pressure during the load increasing stage. For example, for sample $\mathrm{S} 1$ in the first cycle of the experiment, when the injection pressure is $8 \mathrm{MPa}$, the permeability is $0.148 \mathrm{mD}$ during the increasing injection pressure stage, whereas the permeability is $0.166 \mathrm{mD}$ during the decreasing injection pressure stage.

(2) Figure 3 also shows that, for adjacent cycle experiments, the permeability curves overlap but do not completely coincide with each other. At each point with the same injection pressure, the permeability during the injection pressure loading stage is smaller than that during the unloading stage. For adjacent cycle experiments, the differences in the permeability values are very small for the last two cycles of the experiment, Cycle 2 and Cycle 3. Especially for sample S2, these phenomena are quite obvious when the permeability curves of Cycle 2 and Cycle 3 are compared.

The interval between adjacent cycle experiments has an obvious impact on the rock permeability, and this effect can be seen in the permeability values at $4 \mathrm{MPa}$ at the beginning of each experiment. For example, for sample S2, the permeability at the start of Cycle 1 is $0.125 \mathrm{mD}$ at $4 \mathrm{MPa}$. However, after the interval between Cycle 1 and Cycle 2, the permeability value changes to $0.145 \mathrm{mD}$ when Cycle 2 begins at $4 \mathrm{MPa}$.

(3) We use $k_{u}$ to denote the relative permeability increase between two adjacent points with different pressures during 

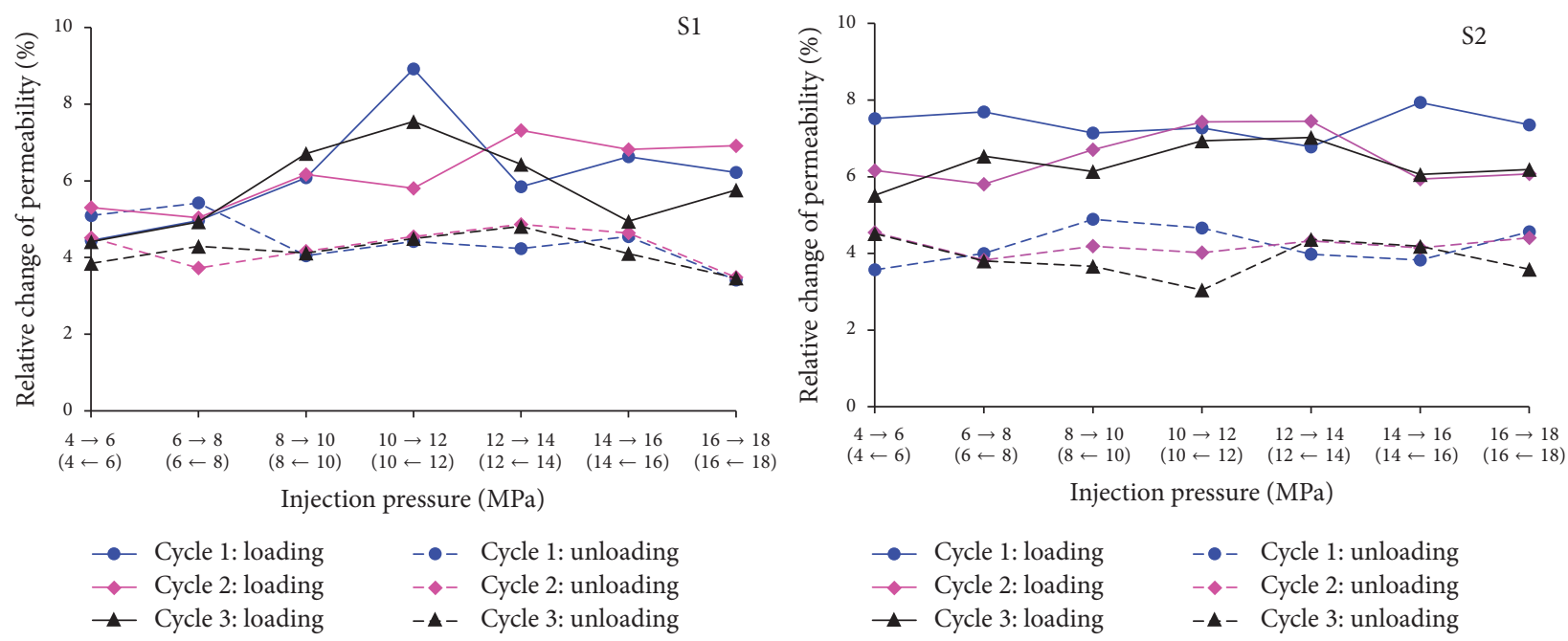

FIGURE 4: Relative changes in permeability under changing injection pressure conditions.

the injection pressure increasing stage for each cycle and $k_{d}$ to denote the relative permeability decrease of the rock samples during the unloading stage.

$$
\begin{aligned}
& k_{u}=\frac{k_{i+1}-k_{i}}{k_{i}} \times 100 \%, \\
& k_{d}=\frac{k_{j}-k_{j+1}}{k_{j}} \times 100 \%,
\end{aligned}
$$

where $k_{i}$ and $k_{i+1}$ represent the rock permeability values at two adjacent points $i$ and $i+1$ with different pressures during the injection pressure loading stage in each cycle and $k_{j}$ and $k_{j+1}$ represent the permeability values at two adjacent points $j$ and $j+1$ with different pressures during the injection pressure unloading stage.

The relative changes in rock permeability are shown in Figure 4.

Figure 4 shows that the increases in relative permeability range from $5 \%$ to $8 \%$ during the injection pressure loading stage and that the decrease in relative permeability ranges from $3 \%$ to $5 \%$ during the unloading stage. The variations are stable in both directions. For example, for sample S2, during Cycle 1, the maximum and minimum permeability changes are $7.94 \%$ and $6.78 \%$, respectively, during the injection pressure loading stage. In contrast, the maximum and minimum permeability changes are $4.89 \%$ and $3.83 \%$, respectively, during the unloading stage.

(4) For each cycle, we use $\Delta k$ to denote the change in permeability at the same injection pressure during the injection pressure loading stage and the unloading stage.

$$
\Delta k=\frac{k_{j}-k_{s}}{k_{s}} \times 100 \%,
$$

where $k_{s}$ and $k_{j}$ denote the rock permeability under the same injection pressure conditions during the injection pressure loading and unloading stages, respectively, for each cycle.

Figure 5 shows the change in permeability of the two samples as a function of the injection pressure for each cycle.
In Figure 5, the permeability changes in sample S2 for Cycle 1, Cycle 2, and Cycle 3 are 21.80\%, 15.07\%, and 16.55\%, respectively, at $4 \mathrm{MPa}$ and $2.45 \%, 1.40 \%$, and $2.38 \%$ at $16 \mathrm{MPa}$, respectively. The change in permeability obviously decreases with increasing injection pressure. Therefore, the changes in permeability in higher-pressure zones are smaller than those in lower-pressure zones.

\subsubsection{Construction of a Mathematical Model Describing the} Relationship between Permeability and Injection Pressure. Based on the experimental results, the changes in permeability with the injection pressure have been analyzed in the preceding part of the text. Various mathematical models are tried to fit the experimental results, such as linear model, exponential model, power function model, and other forms. The variance is used to determine the fitting degree of experimental data and mathematical models. At last, we found that the exponential model that has the highest fitting degree between the injection pressure and the permeability was obtained:

$$
k=k_{0} e^{a P}
$$

where $k$ is the rock permeability, $\mathrm{mD} ; k_{0}$ is the initial permeability, $\mathrm{mD}$; $P$ is the injection pressure, $\mathrm{MPa}$; and $a$ is a parameter obtained by fitting curves to the data.

In the first cycle experiment, the relationship and fitting curves between the permeability and the injection pressure during the pressure loading and unloading stages are shown in Figure 6.

All the mathematical models of the rock permeability and injection pressure for the two samples derived from the three cycle experiments are shown in Table 2 . The quality of the fit to the data is high, and the average of the correlation coefficient $R^{2}$ values is $99.81 \%$.

During the process of increasing and decreasing the injection pressure, the mathematical models obtained from different cycles are different. Thus, we should not expect a mathematical model obtained from one experiment to 

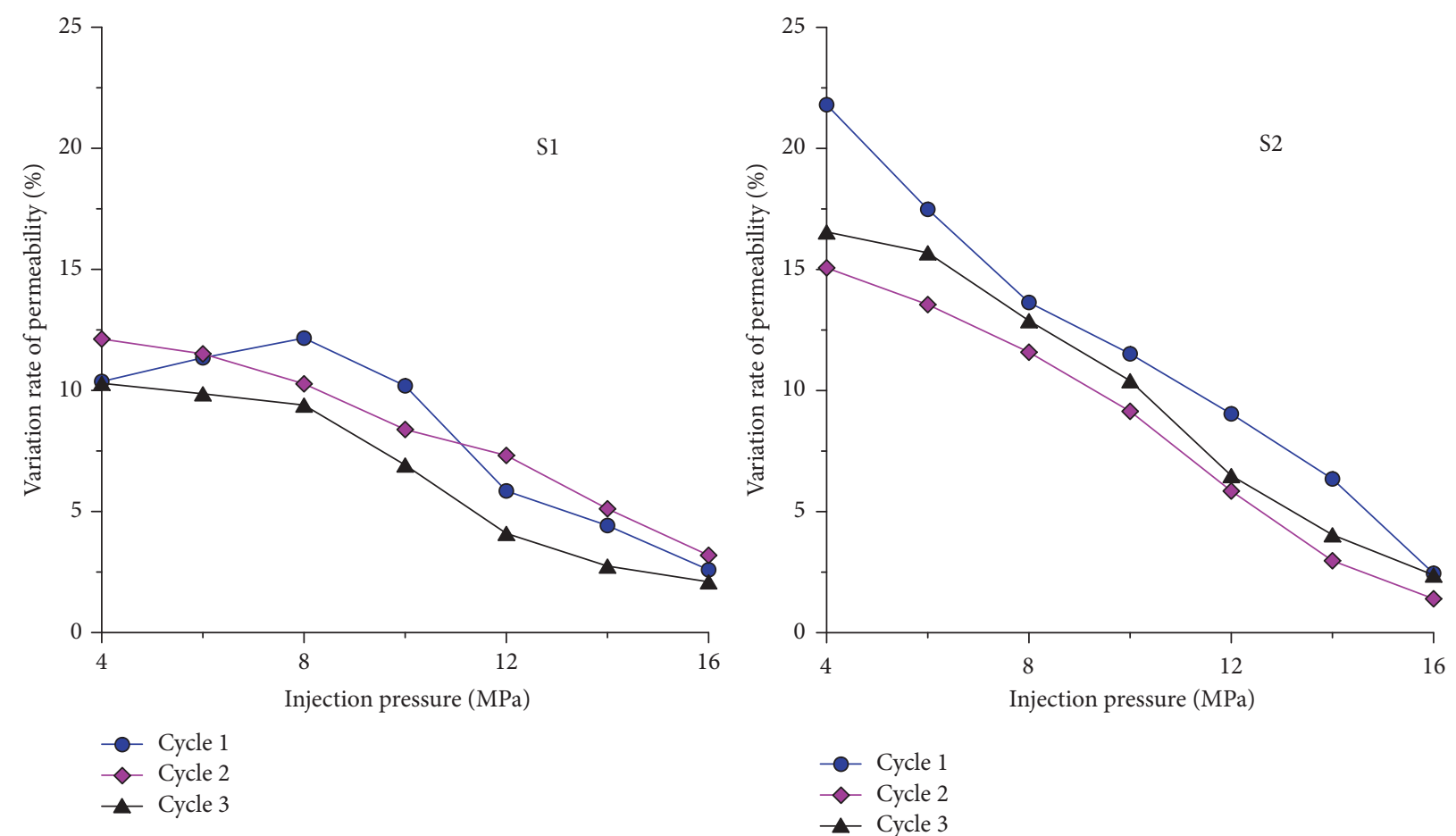

FIGURE 5: The relationship between the change in permeability and the injection pressure for each cycle experiment.
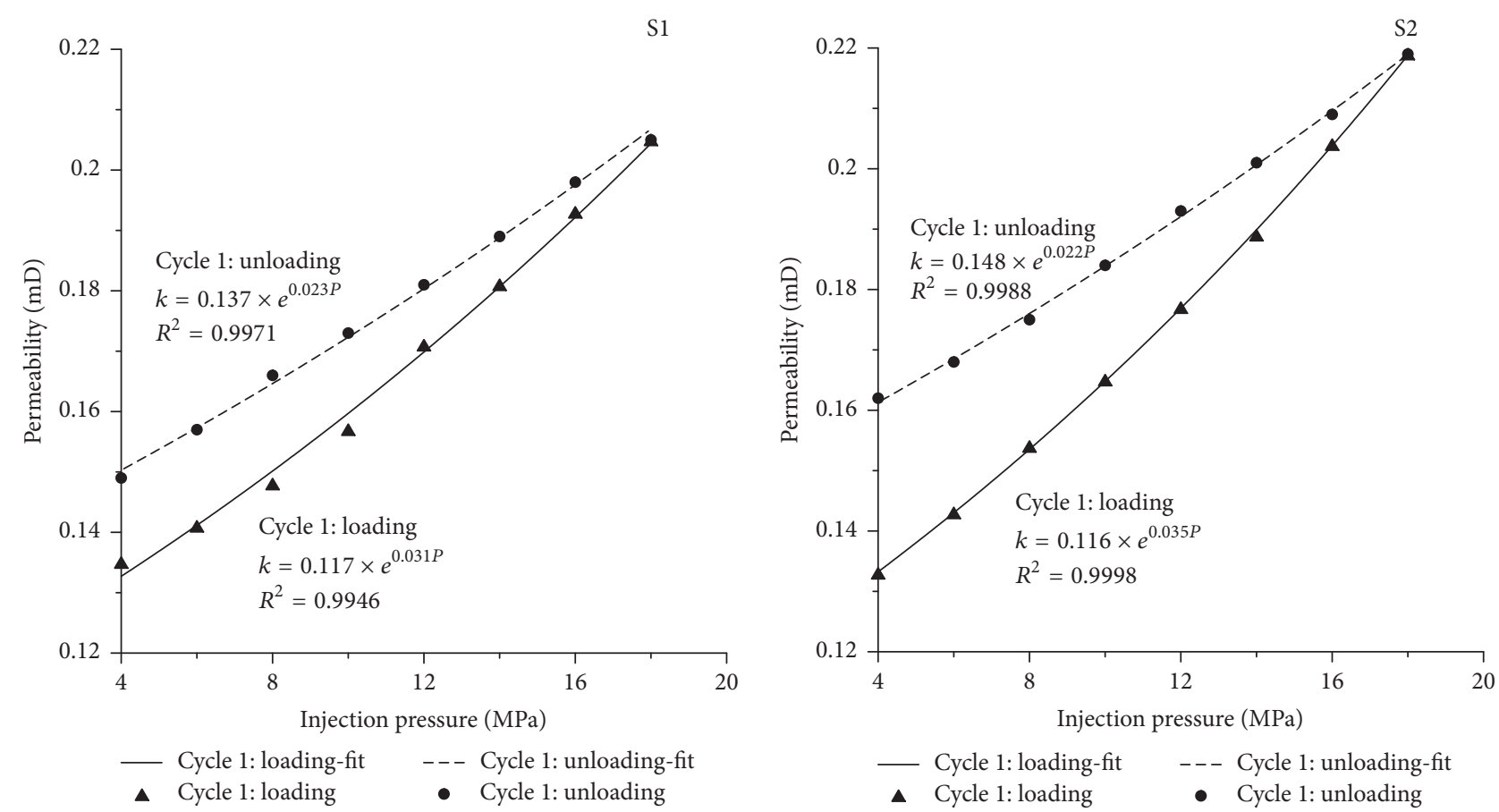

FIGURE 6: Fitting curves and mathematical models describing the relationship between the permeability and the injection pressure for the first cycle experiments.

accurately predict the permeability change at another time or under another set of operating conditions. But Figure 3 shows that, under the condition of changing injection pressure, the permeability can recover during the 24-hour interval, and the permeability curves of different cycles nearly overlap. The rock deformation caused by the injection pressure change is elastic deformation. Thus, to a real engineer, each of the three permeability curves can be used to represent the relationship between the permeability and injection pressure for reservoir simulation. 
TABLE 2: The fitting parameters in the mathematical models describing the relationship between permeability and injection pressure.

\begin{tabular}{|c|c|c|c|c|c|}
\hline Sample & Cycle & Process & $k_{0}$ & $a$ & $R^{2}$ \\
\hline \multirow{6}{*}{ S1 } & \multirow{2}{*}{1} & Loading & 0.117 & 0.031 & 0.9946 \\
\hline & & Unloading & 0.137 & 0.023 & 0.9971 \\
\hline & \multirow{2}{*}{2} & Loading & 0.116 & 0.030 & 0.9964 \\
\hline & & Unloading & 0.135 & 0.022 & 0.9987 \\
\hline & \multirow{2}{*}{3} & Loading & 0.120 & 0.029 & 0.9961 \\
\hline & & Unloading & 0.137 & 0.022 & 0.9990 \\
\hline \multirow{6}{*}{ S2 } & \multirow{2}{*}{1} & Loading & 0.116 & 0.035 & 0.9998 \\
\hline & & Unloading & 0.148 & 0.022 & 0.9988 \\
\hline & \multirow{2}{*}{2} & Loading & 0.128 & 0.032 & 0.9988 \\
\hline & & Unloading & 0.154 & 0.021 & 0.9998 \\
\hline & \multirow{2}{*}{3} & Loading & 0.127 & 0.031 & 0.9994 \\
\hline & & Unloading & 0.157 & 0.020 & 0.9986 \\
\hline
\end{tabular}

\subsection{Influence of Changes in Confining Pressure on Permeability}

\subsubsection{Variation of Permeability under Changes in Confining} Pressure. Figure 7 shows the variation in rock permeability with changing confining pressure in three cycles of increasing and decreasing confining pressure under a constant injection pressure.

The following observations can be made.

(1) Figure 7 shows that rock permeability decreases with increasing confining pressure in each cycle experiment and that the permeability and confining pressure are negatively correlated. With decreasing confining pressure, the permeability of the rock gradually recovers. However, the sample does not achieve the same permeability it had at the same confining pressure during the loading stage. In other words, the rock permeability does not recover fully during the confining pressure unloading stage. For example, for sample S1 with a confining pressure of $10 \mathrm{MPa}$, the permeability is $0.0833 \mathrm{mD}$ during the confining pressure loading stage but $0.0763 \mathrm{mD}$ during the unloading stage.

(2) Figure 7 also shows that the permeability curves do not overlap with each other during the three cycle experiments. The permeability curves of later cycles are always lower than the previous one. Thus, the permeability shows a significant decline in response to the cyclic changes. Hence, deformation of the rock specimen occurs under confining pressure, and the deformation decreased as the confining pressure is progressively removed. However, the recovery process takes a long time, and the samples do not fully recover during the confining pressure unloading process. Moreover, the initial permeability of subsequent cycles differs from the initial permeability. Thus, the permeability of the rock samples does not recover completely within the 24 -hour interval between adjacent cycles.

(3) We use $k_{u}$ to denote the relative permeability decrease between two adjacent points with different pressures in the confining pressure loading stage for each cycle and $k_{d}$ to denote the rock relative permeability increase in unloading stage.

$$
\begin{aligned}
& k_{u}=\frac{k_{i}-k_{i+1}}{k_{i}} \times 100 \%, \\
& k_{d}=\frac{k_{j+1}-k_{j}}{k_{j}} \times 100 \%,
\end{aligned}
$$

where $k_{i}$ and $k_{i+1}$ represent the rock permeability at two adjacent points with different pressures of $i$ and $i+1$, respectively, during the confining pressure loading stage for each cycle and $k_{j}$ and $k_{j+1}$ represent the permeability at two adjacent points $j$ and $j+1$, respectively, with different pressures during the unloading stage.

The relative changes in rock permeability are shown in Figure 8.

Figure 8 shows that the range of permeability values obtained under lower-pressure conditions is larger than that under higher-pressure conditions. For example, for sample S2, the relative changes in permeability in the three cycle experiments are $5.50 \%, 2.31 \%$, and $2.17 \%$ when the confining pressure increases from $8 \mathrm{MPa}$ to $10 \mathrm{MPa}$ but $1.16 \%, 1.00 \%$, and $0.81 \%$ when the confining pressure increases from $16 \mathrm{MPa}$ to $18 \mathrm{MPa}$. The relative changes in permeability decrease with increasing confining pressure, and the change in permeability in the first confining pressure loading stage is clearly larger than in the other two stages. Therefore, during the first confining pressure loading phase, the size of the microcracks and pore throats, which represent the main channels for fluid flow in low-permeability rocks [23], changed substantially. This change resulted in a significant decrease in permeability (Figure 7).

(4) For each cycle experiment, we use $\Delta k$ to denote the change in permeability at the same confining pressure during the confining pressure loading and unloading stages.

$$
\Delta k=\frac{k_{s}-k_{j}}{k_{s}} \times 100 \%,
$$

where $k_{s}$ and $k_{j}$ denote the rock permeability under the same injection pressure conditions during the confining pressure 

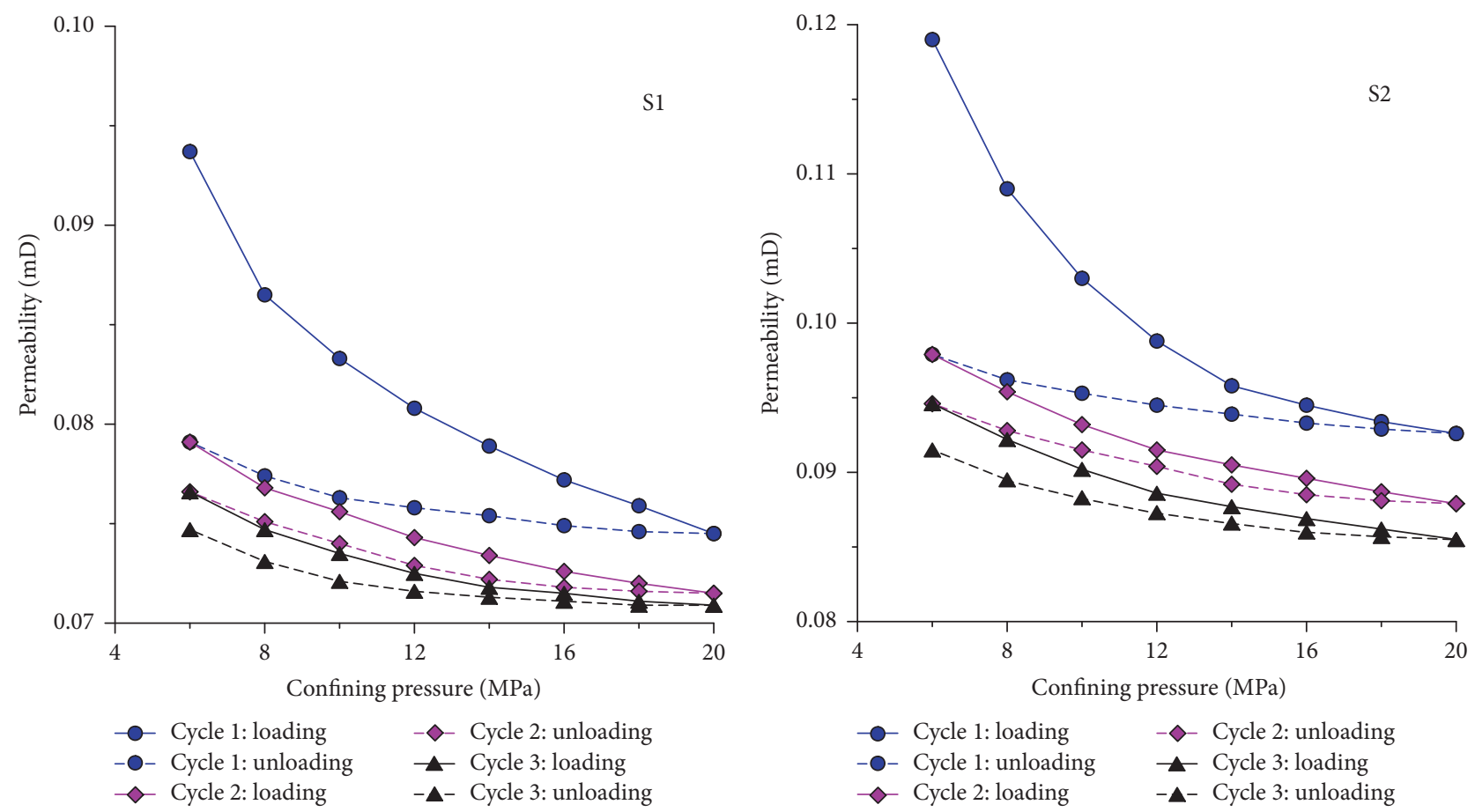

FIGURE 7: Relationship between permeability and confining pressure under constant injection pressure.
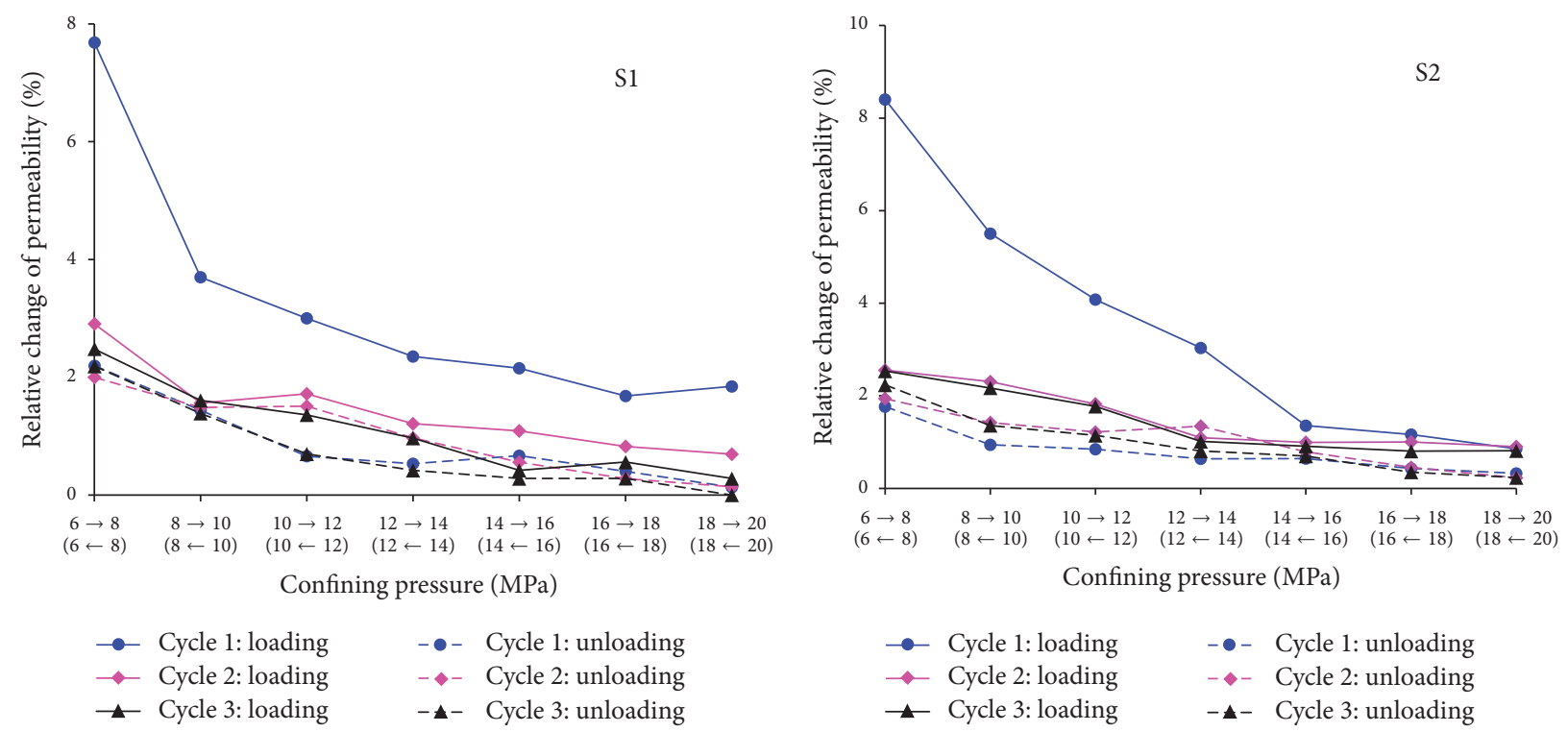

FIGURE 8: The relationships between relative changes in permeability and confining pressure.

loading and unloading stages, respectively, for each cycle experiment.

Figure 9 shows the change in permeability of the two samples as a function of the confining pressure in each cycle.

Figure 9 shows that, for each confining pressure cycling process, the changes in permeability are smaller in the highpressure zone than in the low-pressure zone. The changes in the first cycle are quite significant compared to the other two cycles. The differences in the changes in permeability during Cycle 2 and Cycle 3 are small, and for sample 2, the two curves tend to overlap each other in Figure 9. This result occurs primarily because the changes in confining pressure cause the rock sample to deform, leading to substantial changes in permeability (Figure 7) in the first confining pressure cycle. In addition, the deformation does not reverse, even though there is a 24-hour interval between adjacent cycles. For example, for sample S2, when the confining pressure is $6 \mathrm{MPa}$, the changes in permeability in Cycles 1, 2, and 3 are $17.73 \%, 2.73 \%$, and $2.93 \%$, respectively. The changes in permeability in Cycle 2 and Cycle 3 are far less than that in Cycle 1. 

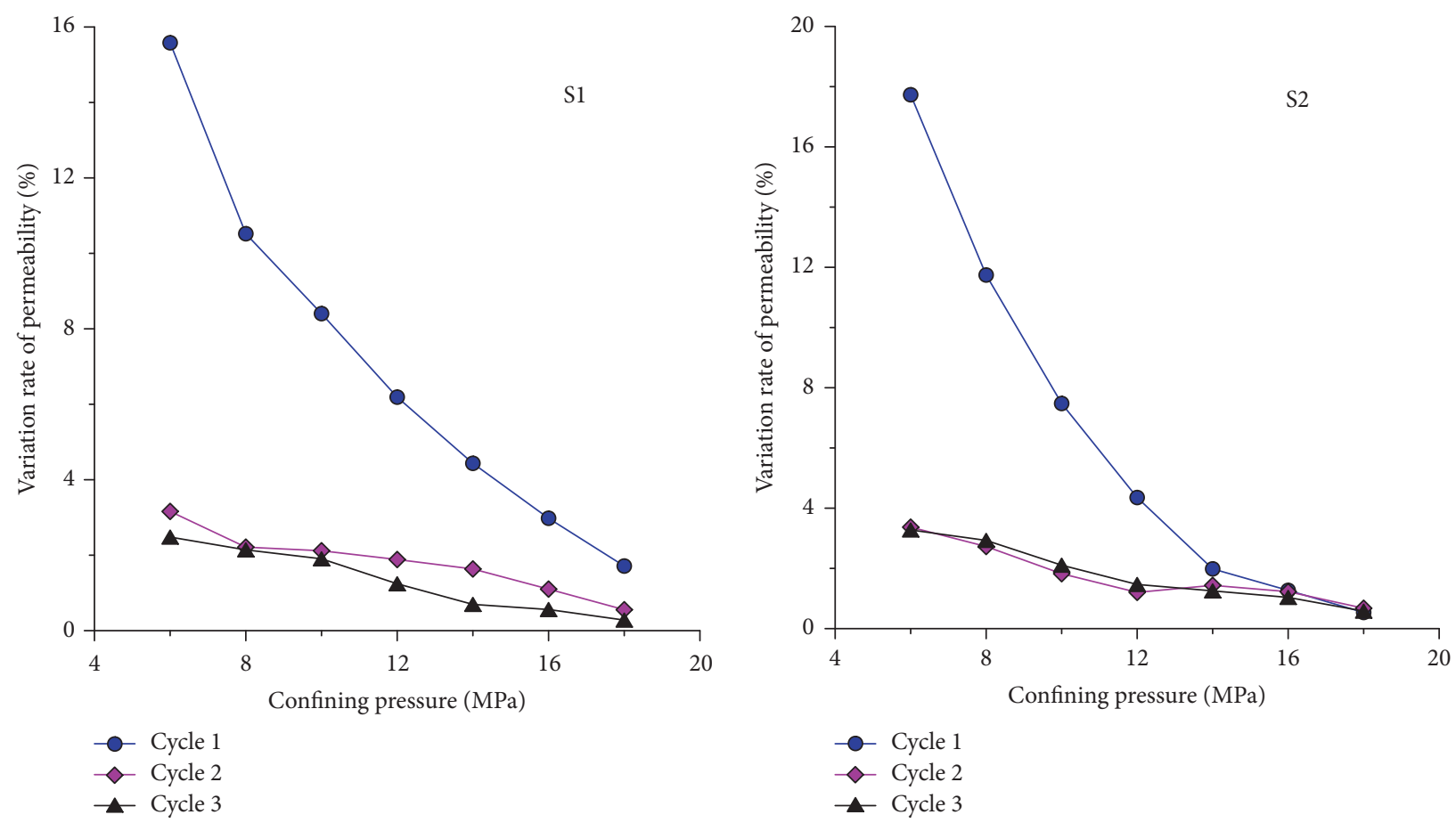

FIGURE 9: The relationship between changes in permeability and confining pressure in each cycle.

3.2.2. Construction of a Mathematical Model Describing the Relationship between Permeability and Confining Pressure. Based on the experimental results, the changes in permeability with confining pressure have been analyzed in the preceding part of the text. Different mathematical models are tried to fit the experimental results, such as linear model, exponential model, power function model, and other forms. The variance is used to determine the fitting degree of experimental data and mathematical models. The following fitting relationship between the confining pressure and the permeability was obtained:

$$
k=k_{0} P_{c}^{a}
$$

where $k$ is the rock permeability, $\mathrm{mD} ; k_{0}$ is the initial permeability, $\mathrm{mD} ; P$ is the confining pressure, $\mathrm{MPa}$; and $a$ is the parameter obtained by fitting curves to the data.

The relationships and fitting curves between the permeability and the confining pressure during the pressure loading and unloading stages in the first cycle experiment are shown in Figure 10.

All the mathematical models describing the relationship between the rock permeability and confining pressure for the two samples in the three cycle experiments are shown in Table 3. The quality of the fit to the data is high, and the average $R^{2}$ value is $97.86 \%$.

Table 3 shows that, even for the same sample, the mathematical models obtained from different cycles of increasing and decreasing the confining pressure are different. Thus, we should not expect a mathematical model obtained from one experiment to accurately predict the permeability change at another time or under another set of operating conditions. Under the condition of changing confining pressure, the permeability curves are significantly different for different cycles. The deformation of the rock caused by the confining pressure change is not elastic deformation. Even so, through the permeability curves, the change ranges of the permeability under different conditions can be obtained. The change ranges of permeability can be used as reference values to evaluate the reservoir performance.

3.3. Comparative Analysis of the Influence of Confining Pressure and Injection Pressure on Permeability. Similarities and significant differences exist between the influences of variable injection pressure and variable confining pressure on rock permeability. The following conclusions have been reached.

(1) Both the injection pressure and the confining pressure have significant effects on the rock permeability of the Liujiagou formation. For example, when the injection pressure is varied, the minimum and maximum permeabilities of S1 are $0.132 \mathrm{mD}$ and $0.205 \mathrm{mD}$, respectively. Hence, the maximum permeability is 1.6 times the minimum permeability. In addition, when the confining pressure is varied, the initial permeability of $\mathrm{S} 1$ is $0.0937 \mathrm{mD}$. After three cycles of confining pressure variation, its permeability is $0.0709 \mathrm{mD}$, which is $24 \%$ less than the initial permeability.

(2) A negative correlation exists between the permeability and the confining pressure, but a positive correlation exists between the permeability and the injection pressure. When the injection pressure is varied, the permeability in the loading stage is smaller than that in the unloading stage under the same injection pressure conditions (Figure 3). In contrast, when the confining pressure is varied, the permeability in the loading stage is greater than that in the unloading stage for the same confining pressure conditions (Figure 7). 
TABLE 3: Fitting parameters in the mathematical models of permeability and confining pressure.

\begin{tabular}{|c|c|c|c|c|c|}
\hline Sample & Cycle & Process & $k_{0}$ & $a$ & $R^{2}$ \\
\hline \multirow{6}{*}{ S1 } & \multirow{2}{*}{1} & Loading & 0.128 & -0.182 & 0.9860 \\
\hline & & Unloading & 0.086 & -0.049 & 0.9671 \\
\hline & \multirow{2}{*}{2} & Loading & 0.092 & -0.083 & 0.9968 \\
\hline & & Unloading & 0.085 & -0.060 & 0.9749 \\
\hline & \multirow{2}{*}{3} & Loading & 0.085 & -0.064 & 0.9765 \\
\hline & & Unloading & 0.080 & -0.042 & 0.9219 \\
\hline \multirow{6}{*}{ S2 } & \multirow{2}{*}{1} & Loading & 0.169 & -0.208 & 0.9621 \\
\hline & & Unloading & 0.106 & -0.046 & 0.9935 \\
\hline & \multirow{2}{*}{2} & Loading & 0.115 & -0.089 & 0.9969 \\
\hline & & Unloading & 0.106 & -0.064 & 0.9913 \\
\hline & \multirow{2}{*}{3} & Loading & 0.110 & -0.084 & 0.9943 \\
\hline & & Unloading & 0.101 & -0.057 & 0.9817 \\
\hline
\end{tabular}
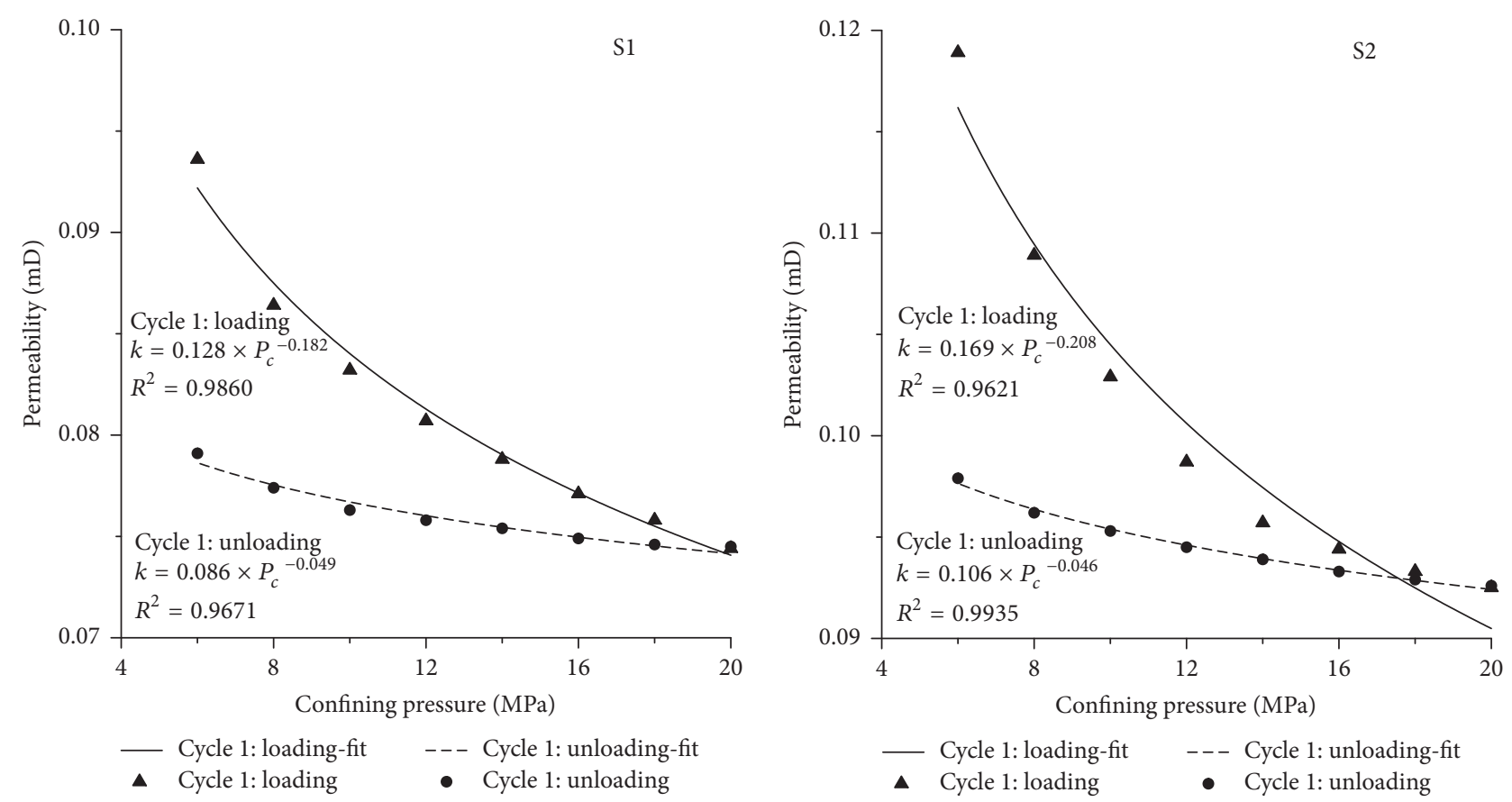

FIGURE 10: Fitting curves and mathematical models of the permeability and the confining pressure for the first cycle experiment.

(3) For the same cycle experiment, the rock permeability curves obtained from the loading stage do not fully overlap with those obtained from the unloading stage, regardless of whether the experiment involves changing the injection pressure or the confining pressure. Thus, even at the same pressure, there are different permeability values. For example, when the injection pressure for sample $\mathrm{S} 2$ is varied in the first cycle experiment, the permeability is $0.143 \mathrm{mD}$ at an injection pressure of $6 \mathrm{MPa}$ during the injection pressure loading stage. The permeability changes to $0.168 \mathrm{mD}$ during the unloading stage, representing a difference of approximately $17 \%$ (Figure 3). In addition, when the confining pressure for sample $\mathrm{S} 2$ is increased to $8 \mathrm{MPa}$ in the first cycle experiment, the difference in the permeability values between the loading stage and the unloading stage is approximately $13 \%$ (Figure 7).
(4) Regardless of whether the confining pressure or the injection pressure is changed, the permeability curves obtained from pairs of adjacent cycle experiments do not overlap each other in the three cycle experiments (Figures 3 and 7). When the confining pressure was changed, the permeability values of later cycles were always smaller than that measured in earlier cycles, and there is no overlap in the area between the curves from different cycle experiments. However, when the injection pressure was changed, the permeability curves of different cycle experiments did overlap.

(5) A comparison of the experimental results under the two stress conditions (changing injection pressure and changing confining pressure) shows that the influence of the interval between adjacent cycles on the initial rock permeability is very different. For a constant injection pressure 
TABLE 4: Measured pore structure parameters of the rock samples before and after the experiments.

\begin{tabular}{lcccccc}
\hline \multirow{2}{*}{ Parameter } & \multicolumn{2}{c}{ S1 } & & \multicolumn{2}{c}{ S2 } & \\
& Initial & Final & Relative change & Initial & Final & Relative change \\
\hline Surface area $\left(\mathrm{m}^{2} / \mathrm{g}\right)$ & 1.7300 & 2.5343 & $46.49 \%$ & 1.5636 & 2.3428 & $49.83 \%$ \\
Total pore volume $(\mathrm{mL} / \mathrm{g})$ & 0.0083 & 0.0082 & $-1.20 \%$ & 0.0079 & 0.0076 & $-3.80 \%$ \\
Micropores volume $(\mathrm{mL} / \mathrm{g})$ & 0.0006 & 0.0010 & $66.67 \%$ & 0.0006 & 0.0009 & $50.00 \%$ \\
Average pore size $(\mathrm{nm})$ & 19.19 & 12.94 & $-32.57 \%$ & 20.21 & 12.98 & $-35.77 \%$ \\
Most probable pore size $(\mathrm{nm})$ & 2.59 & 2.59 & 0 & 2.60 & 2.60 & 0 \\
\hline
\end{tabular}

and changing confining pressure, the initial permeability of the sample decreases with increasing cycle number, and the initial permeabilities of Cycle 2 and Cycle 3 are almost equal to the final permeability of the previous cycle (Figure 7). Therefore, the permeability cannot recover to the initial value of the previous cycle over a 24-hour interval, and the rock sample deformation cannot be reversed. For a constant confining pressure and a changing injection pressure, the initial permeabilities of the three cycles are similar (see sample S1 in Figure 3). The permeability curves of the three cycles show little difference (Figure 3), indicating that the permeability of the rock recovers well during the 24-hour intervening interval. In actual engineering projects, interruptions in the $\mathrm{CO}_{2}$ injection process will cause the injection pressure and confining pressure to increase and decrease many times. Hence, these experimental results have practical significance for actual projects.

\section{Effect of Stress Variation on the Pore Structure of Rock}

The surface area of the rock samples was calculated via the BET equation, which was derived by Brunauer, Emmett, and Teller, by calculating the saturated adsorption amount of the monomolecular layer at relative pressures of 0.05 to $0.35[24,25]$. The most probable pore size was calculated via the $\mathrm{BJH}$ method proposed by Barret, Joyner, and Halenda using the adsorption branch of the adsorption isotherm. The average pore size was calculated from the amount of nitrogen adsorbed when the relative pressure was close to 1 . The pore size distribution, micropore volume, and total pore volume were evaluated via the DFT method [26]. All of the measured parameters are shown in Table 4.

The International Union of Pure and Applied Chemistry (IUPAC) divides pores within materials into three categories: micropores (pores with widths not exceeding approximately $2 \mathrm{~nm}$ ), mesopores (pores with widths between $2 \mathrm{~nm}$ and $50 \mathrm{~nm}$ ), and macropores (pores with widths exceeding approximately $50 \mathrm{~nm}$ ) [27]. According to the test results from samples S1 and S2, the pores in both samples before and after the experiments are mesopores. However, the multistage cycle experiments involving increasing and decreasing the injection and confining pressures exerted significant effects on the pore sizes of the rock samples. The average pore diameters for S1 and S2 decreased from initial values of $19.19 \mathrm{~nm}$ and $20.21 \mathrm{~nm}$ to final values of $12.94 \mathrm{~nm}$ and $12.98 \mathrm{~nm}$, respectively. Hence, the relative changes are $32.57 \%$ and $35.77 \%$, respectively. Simultaneously, the surface areas of the rock samples increased significantly, with relative changes of more than $50 \%$ for both samples.

Figures 11 and 12 show the curves representing the adsorption isotherms of samples S1 and S2, respectively, before and after the experiments. The desorption branch curves clearly deviate from the adsorption curves in places. When the relative pressure $P / P_{0}$ (where $P$ is the current pressure, $\mathrm{MPa}$, and $P_{0}$ is the saturated vapor pressure of nitrogen at $77 \mathrm{~K}$, i.e., approximately $0.101 \mathrm{MPa}$ ) lies within the range 0 to 0.8 , the nitrogen adsorption capacity represented by the isothermal adsorption line increases slowly. When the $P / P_{0}$ value lies within the range $0.8 \sim 1.0$, the nitrogen adsorption capacity increases rapidly. The hysteresis loop transition point appears when $P / P_{0}$ is equal to 0.42 (Bertier et al., 2016). This result indicates that the phenomenon of capillary condensation occurs, and hysteresis loops can be observed when $P / P_{0}>$ 0.42. According to the isotherm classification of the IUPAC [27], the four isotherms are Type I isotherms. Therefore, the pores found in the samples are mainly mesopores. This result is consistent with the previously described results of the average pore size test.

The shape of a hysteresis loop can reflect the pore structure of a rock sample [23]. The IUPAC classifies hysteresis loops into a total of 6 categories of 5 types, specifically $\mathrm{H} 1$, $\mathrm{H} 2$ (a), $\mathrm{H} 2$ (b), H3, H4, and $\mathrm{H} 5$ [27]. In this experiment, the adsorption and desorption branches of samples S1 and S2 were almost identical before and after the experiments. The phenomenon of capillary condensation obviously occurs, and the adsorption curve rises sharply only when the relative pressure is close to the saturated vapor pressure. The hysteresis loops belong to Type H3, reflecting the existence of parallel plate-type slit pores in the rock samples. This result indicates that the multistage cycles of increasing and decreasing the injection pressure and confining pressure did not affect the pore type of the rock samples.

Figure 13 shows the pore size redistribution of samples S1 and S2 before and after the experiment. It can be seen that the multistage cycle experiments, which involved changing the injection pressure and the confining pressure, had significant effects on the pore sizes of the samples. The micropore (pore sizes $<2 \mathrm{~nm}$ ) volumes of S1 and S2 increased by $66.7 \%$ and $50 \%$ after the experiment, respectively. The number of mesopores in the pore size range between 2 and $10 \mathrm{~nm}$ also obviously increased. However, the number of mesopores in the pore size range between 10 and $50 \mathrm{~nm}$ did not obviously change. At the same time, the number of macropores (pore sizes $>50 \mathrm{~nm}$ ) significantly decreased. 

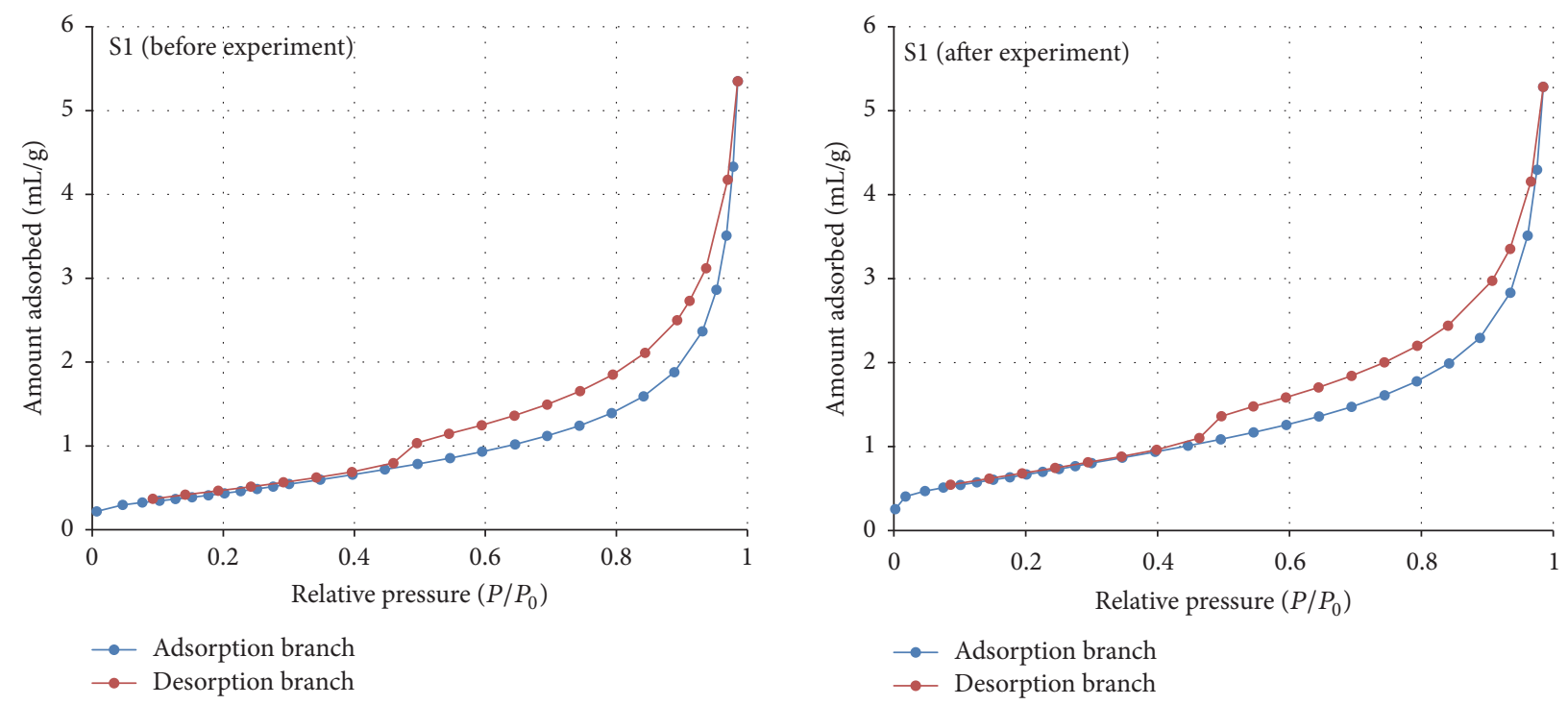

FIGURE 11: $\mathrm{N}_{2}$ adsorption-desorption isotherms of S1.
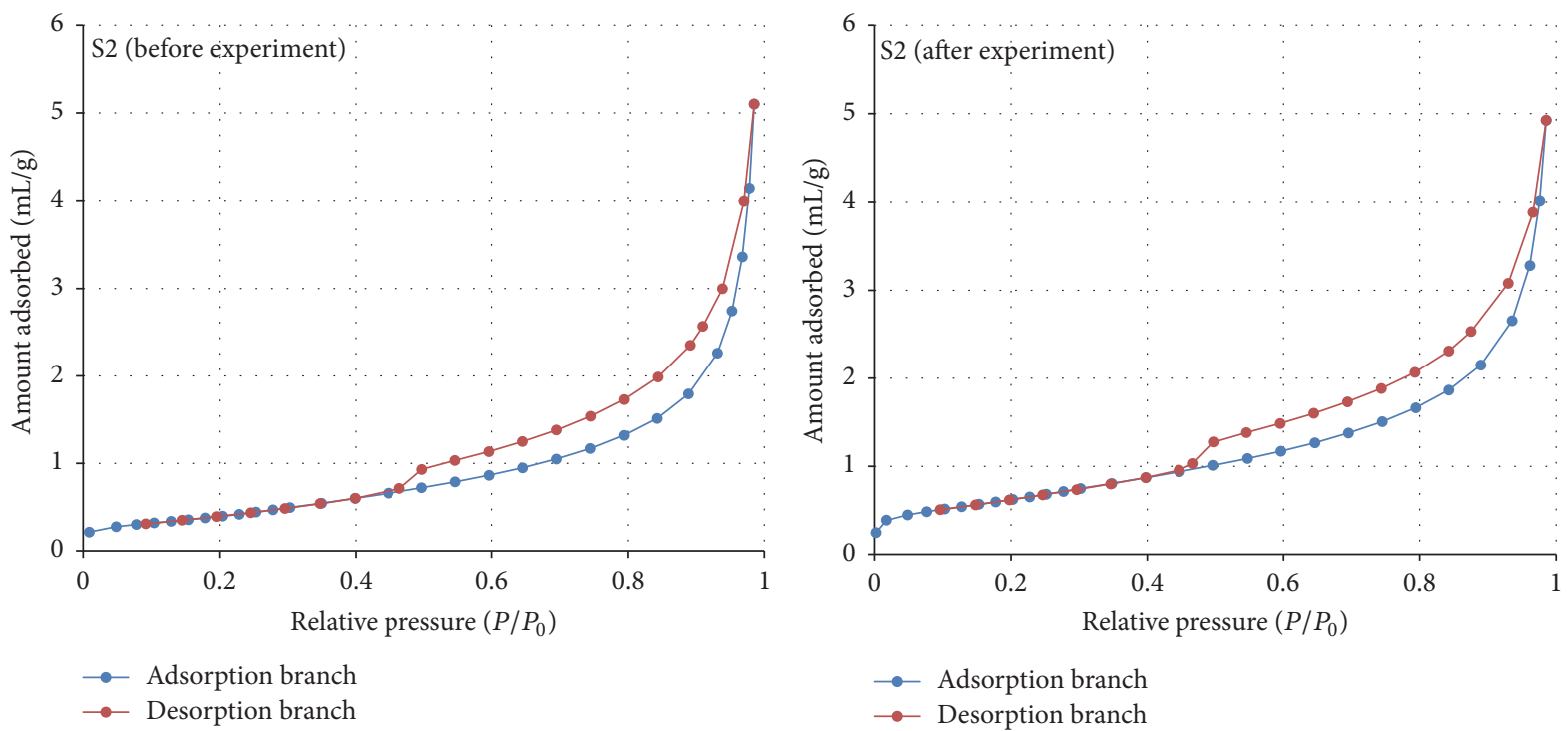

FIGURE 12: $\mathrm{N}_{2}$ adsorption-desorption isotherms of S2.

Figure 14 shows the cumulative pore volume curves of the rock samples before and after the experiments. The cumulative pore volumes of samples S1 and S2 after the experiment are greater than those before the experiment. In the pore diameter range of $0-10 \mathrm{~nm}$, the cumulative pore volume curves after the experiments considerably exceed those measured before the experiments. Subsequently, in the pore diameter range of $10-50 \mathrm{~nm}$, the two curves are nearly parallel. This result indicates that little pore size change occurred in the range of 10-50 $\mathrm{nm}$. For pore sizes greater than $50 \mathrm{~nm}$, the gap between the two curves gradually shrinks. In short, the total pore volumes did not change greatly.

Based on the analysis presented above, the multistage cycle experiments involving changes in the injection and confining pressures had little effect on the pore type of the rock samples. The pores in the rock samples before and after the experiments both belonged to the parallel plate pore type. However, the multistage cycle experiments had significant effects on the pore size distribution. The large increase in surface area indicates that the microstructures of the samples were changed by the multiple cycle stress experiments. As the number and volume of pores smaller than $10 \mathrm{~nm}$ increased, macropores with diameters larger than $50 \mathrm{~nm}$ decreased. The increase in micropores and mesopores did not greatly affect the seepage capacity of the rock. However, the decrease in macropores caused the permeability of the rock sample to decrease substantially. The permeabilities of samples S1 and S2 diminished from initial values of $0.135 \mathrm{mD}$ and 

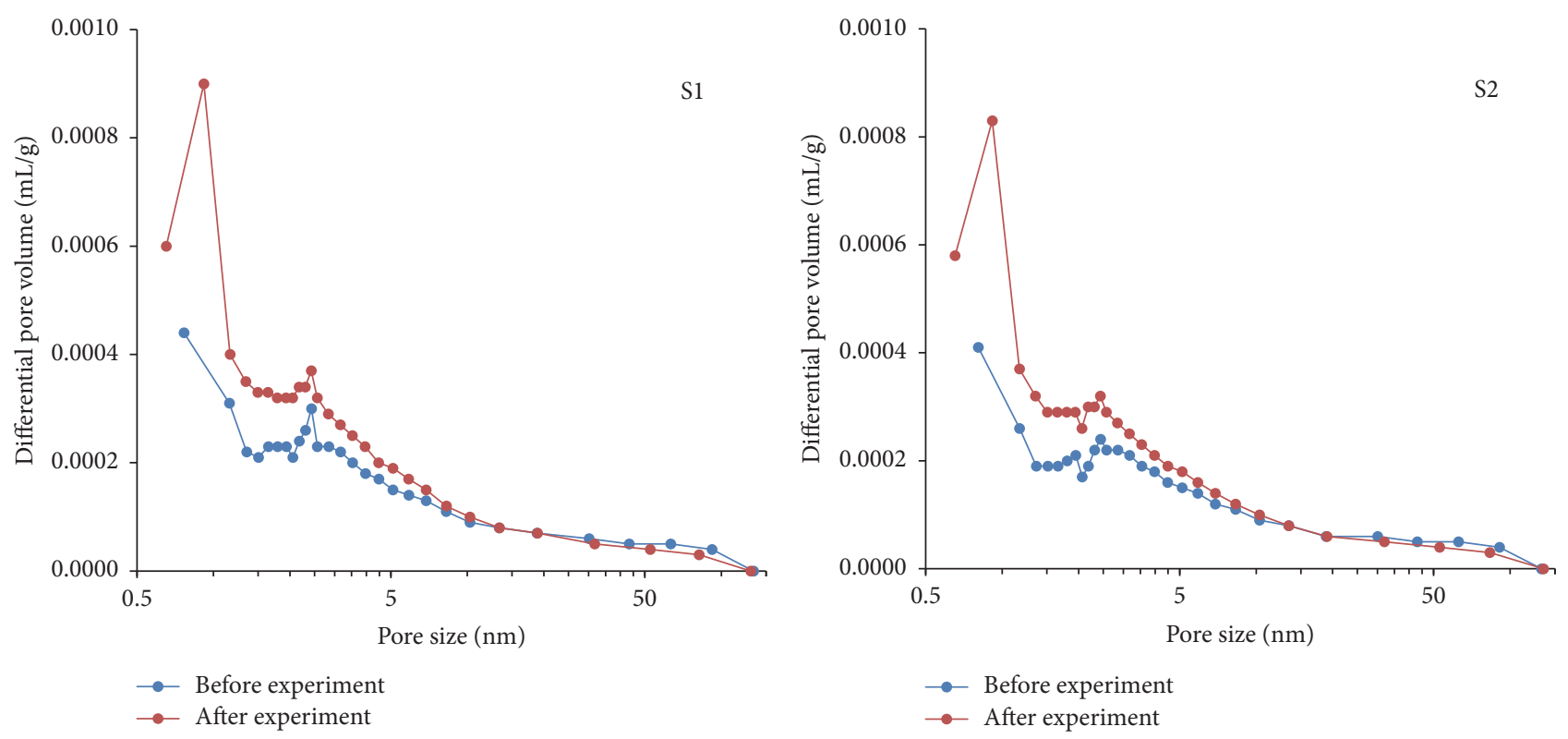

FIgURE 13: Pore size distributions before and after the experiments.
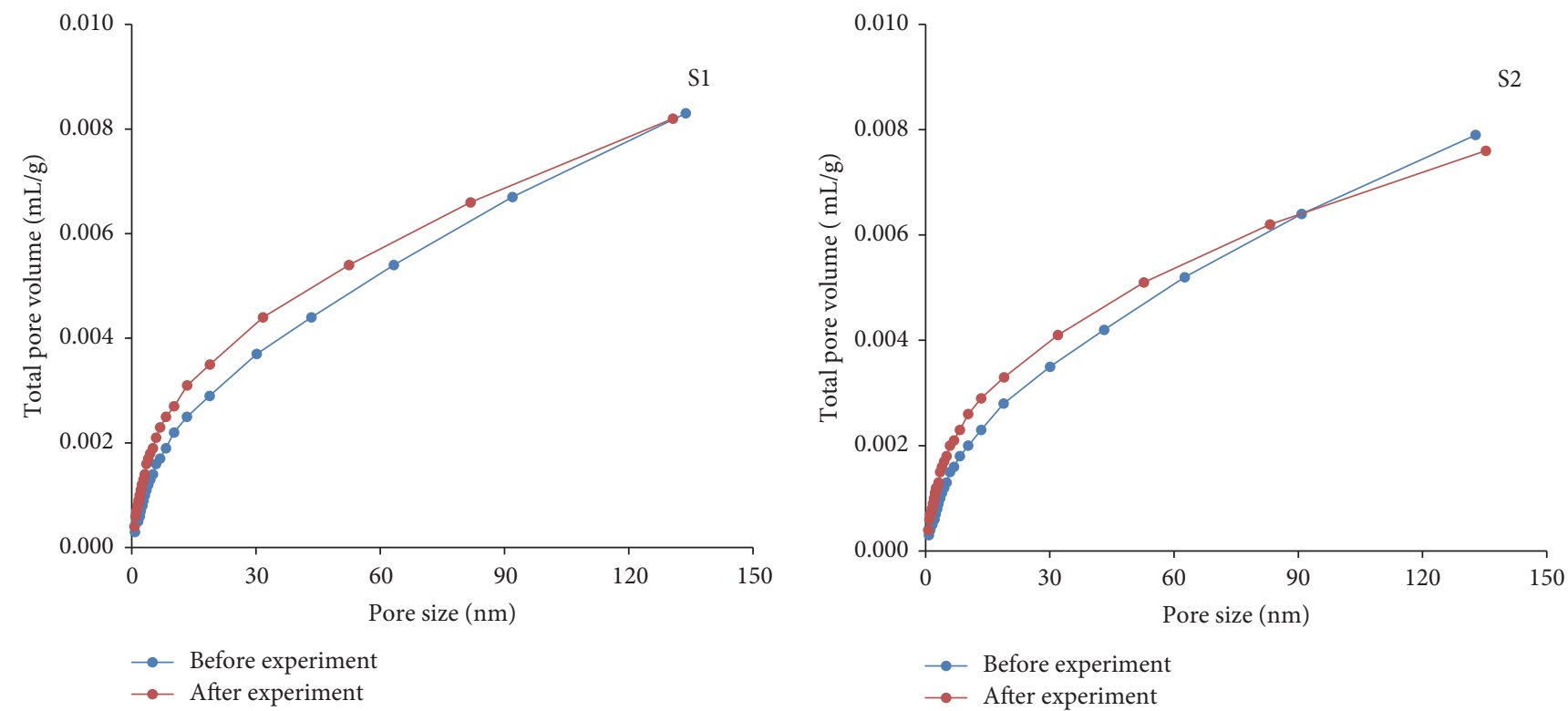

FIGURE 14: Cumulative pore volumes before and after the experiments.

$0.133 \mathrm{mD}$ to $0.0747 \mathrm{mD}$ and $0.0915 \mathrm{mD}$, respectively, after the experiments involving three cycles of increasing and decreasing the injection and confining pressures.

The clay mineral contents of the rock samples influenced the permeability changes. The clay mineral content in S2 is approximately 5 times that in S1. In the first cycle of the injection pressure variation, the average change in permeability was $8.13 \%$ for $\mathrm{S} 1$ and $11.75 \%$ for $\mathrm{S} 2$.

There are more intergranular pores in sample S2, which has a greater clay mineral content, and so that sample is more easily affected by increases in injection pressure, which causes its changes in permeability to be greater than those of sample S1. Under conditions in which the confining pressure changes, the average changes in permeability of S1 and S2 in the first cycle are $7.12 \%$ and $6.44 \%$, respectively. The influence of clay mineral content on the permeability change is more obvious under conditions in which the injection pressure changes than when the confining pressure changes.

Related studies have shown that clay minerals have massive intergranular micropores and interlayer cracks. With the increase of clay mineral content, the micropores content increased. However, since the pore sizes of these micropores are small, when the rock sample was saturated with water, the combination water (consists of weak combination water and 
strong combination water) on the surface of mineral particles would occupy a lot of void seepage channels.

Under the variable injection pressure, when the injection pressure increases, the proportion of the weak combination water which can participate in seepage in a certain pressure gradient would increase gradually. The higher the clay mineral content in the rock samples, the more significant the change in permeability when the injection pressure increases.

Under the variable confining pressure, the injection pressure keeps constant $(4 \mathrm{MPa})$. Under the constant injection pressure, the macropores and mesopores are the main seepage channels. When the confining pressure increases, the size and the volume of the macropores and mesopores decrease, which makes the permeability of the rock sample reduce. The pores inside the clay minerals are mainly micropores filled with combination water; for this reason, they are not the main seepage channels. Hence, its volume change will not have an obvious effect on permeability.

\section{Conclusions and Suggestions}

The following conclusions have been reached based on the experimental study of permeability variations in reservoir rock samples from the Liujiagou formation, one of the reservoirs targeted in the CCS demonstration project in the Ordos Basin.

(1) Both the confining pressure and the injection pressure have significant effects on the permeability of this reservoir rock. The relative permeability changes with pressure and between the loading and unloading stages are higher at low pressures than at high pressures. Changing the confining pressure changes the relative permeability by more than $20 \%$. In addition, changing the injection pressure changes the relative permeability by up to $60 \%$.

(2) A positive correlation exists between injection pressure and permeability, but a negative correlation exists between confining pressure and permeability. Based on the experimental data, highly relevant mathematical models that describe the relationship between permeability and injection pressure or confining pressure can be constructed. However, the results show that the constructed models have important differences. Therefore, we cannot use the mathematical model constructed using data from one experiment to predict the permeability changes in another situation. This aspect should receive more attention in the numerical simulations used in practical engineering.

(3) The multistage and discontinuous nature of the injection process in the geological storage of $\mathrm{CO}_{2}$ means that the effective stress acting on a reservoir will experience repeated loading and unloading. The experimental results show that the initial permeability of the rock is more strongly affected by the changes in the confining pressure compared to changes in the injection pressure. In addition, the effects on rock permeability caused by a changing injection pressure can be diminished by using a sufficiently long injection interval time.

(4) Multistage cycle experiments involving changes in the injection and confining pressures have little effect on the pore types of rock samples, but they have significant effects on the pore size distribution. The total pore volumes of the samples did not change significantly. However, the proportion of lowpermeability micropores and mesopores increased, and the proportion of macropores, representing the main seepage channels, clearly decreased. The above results indicate that the storage capacity of the reservoir will remain stable, but the permeability of the rock will decrease.

(5) The micropore structure of rocks is closely related to the clay minerals in the rocks. For similar rocks with different clay mineral contents, higher clay mineral contents are associated with greater permeability changes during injection pressure variations. The influence of clay mineral contents on permeability changes is more obvious in association with injection pressure changes with confining pressure changes. The injection pressure is a controllable factor in actual CCS projects. Therefore, sufficient attention should be paid to the effects of rock type and clay mineral content on rock permeability in practical CCS projects.

In fact, the permeability of the rock depends on the characters of the material, such as the void space/porous structure, its configuration/volume/geometry, and topology in the medium. These character parameters are stress dependent, but the stress levels are changing in experiment. Therefore, these character parameters are changing, and at the same time, it is difficult to monitor these parameters in real time in an experiment. Due to the heterogeneity of the strata, there is a lot of uncertainty to apply the stress-permeability mathematic model obtained from a rock experiment of a certain strata reservoir to other reservoirs in other sites. That is to say, it is difficult to derive a universal mathematical mode between the permeability and pressure. Thus, the reasonable treatment for a specific stratum reservoir is to take the representative rock sample of the reservoir and obtain the mathematical model between injection pressure and permeability and the permeability change range under the impact of the confining pressure change. And then the mathematical models obtained can be used in the reservoir evaluation.

The focus of this paper is the influence of multiperiod stress changes on rock permeability, so it just considers a single fluid in the experiment. In the actual project of $\mathrm{CO}_{2}$ geological storage, the underground fluid is mixed phase fluid containing $\mathrm{CO}_{2}$ [28]. The complexity will greatly increase. The chemical reactions between $\mathrm{CO}_{2}$ and minerals will also affect the pore structure of the rock, which in turn affects the permeability of the rock. Further studies should explore the effect of mixed fluids, multiphase fluids, and the chemical reactions on rock permeability under different stress conditions. In addition, the influence of pressure on rock deformation should be analyzed according to the stressstrain curve of rock.

\section{Conflicts of Interest}

The authors declare that they have no conflicts of interest.

\section{Acknowledgments}

This work was supported by the National Natural Science Foundation of China (Grants nos. 41502258 and 41172205), by 
a geological survey project (Grant no. 121201012000150010), by China National Science and Technology Major Project (Grant no. 2016ZX05016-005), and by the Graduate Innovation Fund of Jilin University (Grant no. 2016205).

\section{References}

[1] J. Guo, D. Wen, S. Zhang et al., "Potential evaluation and demonstration project of $\mathrm{CO}_{2}$ geological storage in China," Tech. Rep. 2, Geological Survey of China, 2015.

[2] Z. Meng, H. Guo, Q. Liu, B. Jiang, and H. Li, "Microscopic pore structure for tight sandstone gas reservoirs in Tarim Basin," Journal of Central South University, vol. 46, no. 8, pp. 3032-3039, 2015.

[3] F. Wang, Z. Sun, H. Liu, T. Xu, and J. Jing, "Experimental study on the variation of permeability of medium-fine feldsparquartz sandstone low-permeability reservoir under the circulatory increasing or reducing conditions of confining pressure," Journal of Hydraulic Engineering, vol. 47, no. 9, pp. 1125-1132, 2016.

[4] A. Amann-Hildenbrand, J. P. Dietrichs, and B. M. Krooss, "Effective gas permeability of tight gas sandstones as a function of capillary pressure-a non-steady-state approach," Geofluids, vol. 16, no. 3, pp. 367-383, 2016.

[5] Y. Huang and E. Wang, "Experimental study of the laws between the effective confirming pressure and rock permeability," Journal of Tsinghua University, vol. 47, no. 3, pp. 340-343, 2007.

[6] I. Fatt and D. Davis, "Reduction in permeability with overburden pressure," Journal of Petroleum Technology, vol. 4, article 16, 1952.

[7] A. McLatchie, R. Hemstock, and J. Young, "The effective compressibility of reservoir rock and its effects on permeability," Journal of Petroleum Technology, vol. 10, pp. 49-51, 1958.

[8] Z. Wu, H. Zhou, J. Ding, L. Ran, and H. Yi, "Research on permeability testing of rock salt under different permeability pressures," Chinese Journal of Rock Mechanics and Engineering, vol. 31, no. 2, pp. 3740-3746, 2012.

[9] J.-X. Wang, L.-S. Hu, C. Ye, Y.-Q. Tang, and P. Yang, “Triaxial permeability test of marble under complex stress path," Rock and Soil Mechanics, vol. 31, no. 8, pp. 2389-2398, 2010.

[10] J. Vairogs, C. L. Hearn, D. W. Dareing, and V. W. Rhoads, "Effect of rock stress on gas production from low-permeability reservoirs," Journal of Petroleum Technology, vol. 23, no. 9, pp. 1161-1167, 1971.

[11] X.-C. Xue, Y.-D. Yan, Z.-Y. Geng, and Y.-P. Zhou, "Study on stress sensitivity of low permeability sandstone reservoir," Liaoning Chemical Industry, vol. 44, pp. 1147-1149, 2015.

[12] S. Peng, Z. Meng, H. Wang, C. Ma, and J. Pan, “Testing study on pore ratio and permeability of sandstone under different confining pressures," Chinese Journal of Rock Mechanics and Engineering, vol. 22, no. 5, pp. 742-746, 2003.

[13] J. B. Jennings, H. B. Carroll, and C. J. Raible, "Relationship of permeability to confining pressure in low permeability rock," in Proceedings of the SPE/DOE Low Permeability Gas Reservoirs Symposium, pp. 391-398, Society of Petroleum Engineers, Denver, Colorado, March 1983.

[14] H. Wang, W. Xu, J. Zuo, J. Shao, and C. Jia, "Evolution law of the permeability and porosity for low-permeability rock based on gas permeability test," Journal of Hydraulic Engineering, vol. 46, no. 2, pp. 208-216, 2015.
[15] L. Lan, Y. Kang, Y. Chen et al., "Discussion on evaluation methods for stress sensitivities of low permeability and tight sandstone reservoirs," Drilling Fluid and Completion Fluid, vol. 22, article 79, 2005.

[16] A. P. Byrnes, K. Sampath, and P. Randolph, "Effect of pressure and water saturation on permeability of western tight sandstones," in Proceedings of the 5th Annual DOE Symposium on Enhanced Oil and Gas Recovery and Improved Drilling Technology, pp. 22-24, Elsevier Science, Tulsa, Okla, USA, 1979.

[17] W. Wang, W. Xu, R. Wang, Y. Cao, H. Wang, and S. Feng, "Permeability of dense rock under triaxial compression," Chinese Journal of Rock Mechanics and Engineering, vol. 34, no. 1, pp. 40-47, 2015.

[18] K. Wang, T. Xu, H. Tian, and F. Wang, "Impacts of mineralogical compositions on different trapping mechanisms during longterm $\mathrm{CO}_{2}$ storage in deep saline aquifers," Acta Geotechnica, vol. 11, no. 5, pp. 1167-1188, 2016.

[19] W. Kong, B. Bai, X. Li, and N. Wei, "Sealing efficiency of combined caprock for $\mathrm{CO}_{2}$ storage in saline aquifer," Chinese Journal of Rock Mechanics and Engineering, vol. 34, pp. 26712678, 2015.

[20] F. Wang, J. Jing, T. Xu, Y. Yang, and G. Jin, "Impacts of stratum dip angle on $\mathrm{CO} 2$ geological storage amount and security," Greenhouse Gases: Science and Technology, vol. 6, no. 5, pp. 682694, 2016.

[21] F. Bu, T. Xu, F. Wang, Z. Yang, and H. Tian, "Influence of highly permeable faults within a low-porosity and low-permeability reservoir on migration and storage of injected $\mathrm{CO}_{2}$," Geofluids, vol. 16, no. 4, pp. 769-781, 2016.

[22] Z. Zhang and Z. Yang, "Theoretical and practical discussion of measurement accuracy for physisorption with micro- and mesoporous materials," Chinese Journal of Catalysis, vol. 34, no. 10, pp. 1797-1810, 2013.

[23] F. Yang, Z. Ning, C. Hu, B. Wang, K. Peng, and H. Liu, "Characterization of microscopic pore structures in shale reservoirs," Acta petrolei sinica, vol. 34, pp. 301-311, 2013.

[24] H. Tian, S. Zhang, S. Liu, and H. Zhang, "Determination of organic-rich shale pore features by mercury injection and gas adsorption methods," Acta Petrolei Sinica, vol. 33, no. 3, pp. 419427, 2012

[25] Z. Xiaojun and C. Jingong, "Progress and significance of research on relation between specific surface area and organic matter in argillaceous source rocks," Oil \& Gas Geology, vol. 3, p. 008, 2012.

[26] J. Jagiello and M. Thommes, "Comparison of DFT characterization methods based on $\mathrm{N}_{2}, \mathrm{Ar}, \mathrm{CO}_{2}$, and $\mathrm{H}_{2}$ adsorption applied to carbons with various pore size distributions," Carbon, vol. 42, pp. 1227-1232, 2004.

[27] M. Thommes, K. Kaneko, A. V. Neimark et al., "Physisorption of gases, with special reference to the evaluation of surface area and pore size distribution (IUPAC Technical Report)," Pure and Applied Chemistry, vol. 87, no. 9-10, pp. 1051-1069, 2015.

[28] L. K. Abidoye, K. J. Khudaida, and D. B. Das, "Geological carbon sequestration in the context of two-phase flow in porous media: a review," Critical Reviews in Environmental Science and Technology, vol. 45, no. 11, pp. 1105-1147, 2015. 

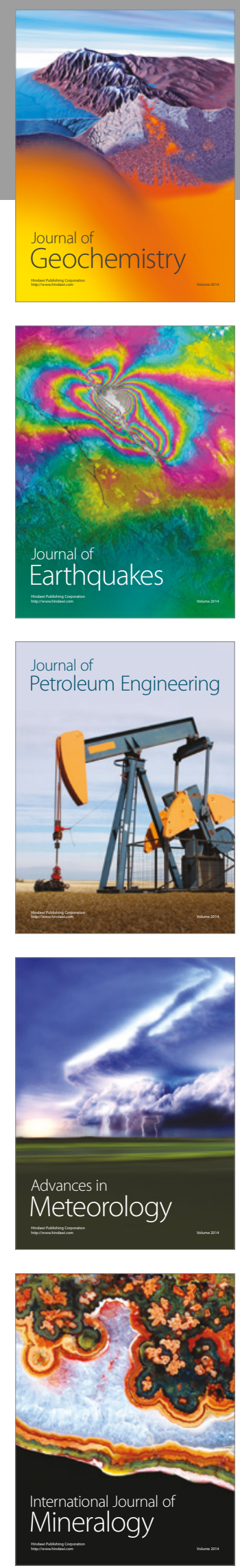
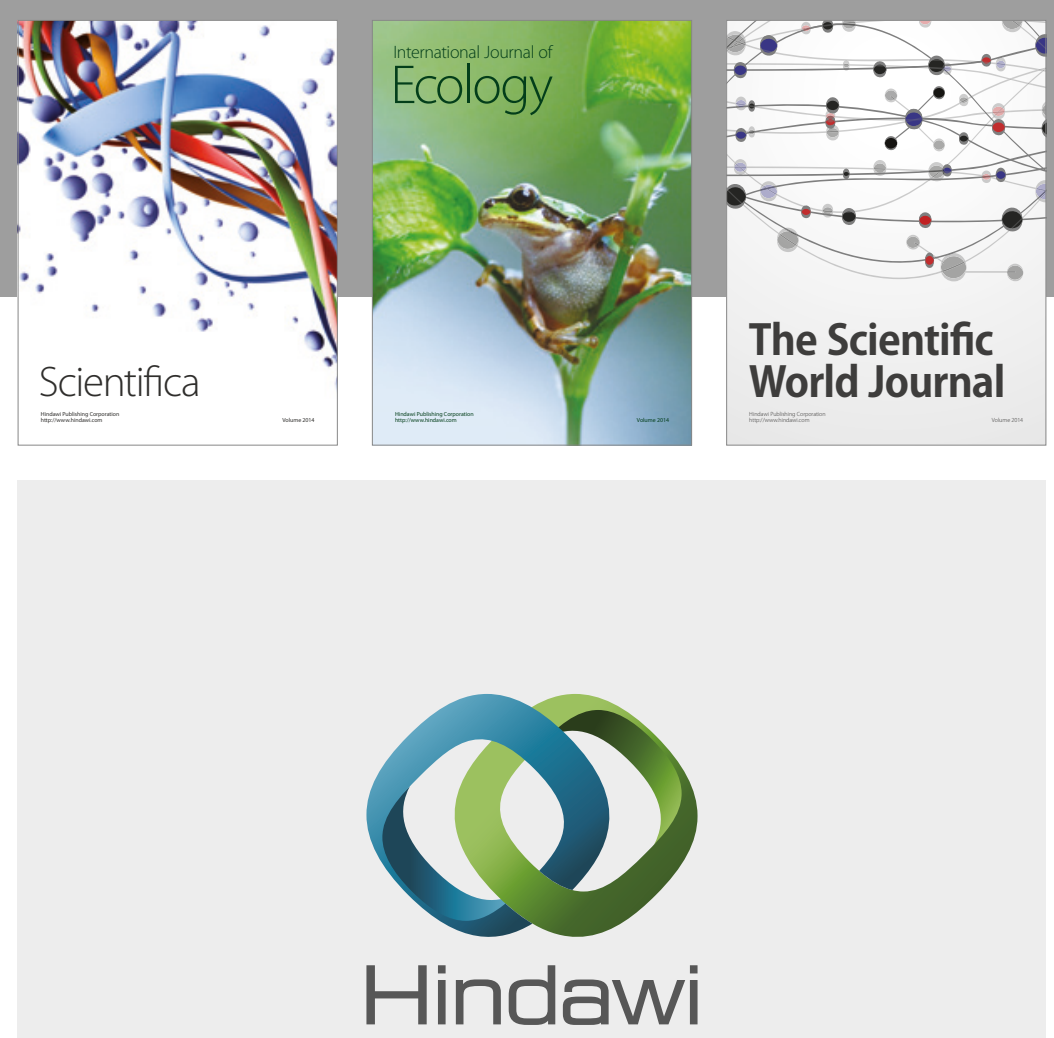

Submit your manuscripts at

https://www.hindawi.com
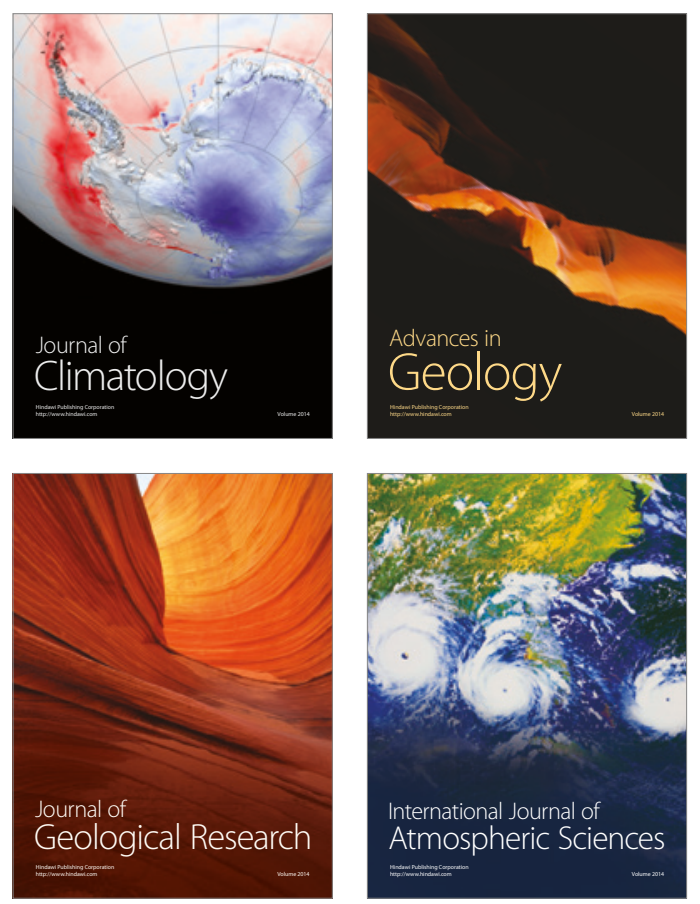

The Scientific

World Journal
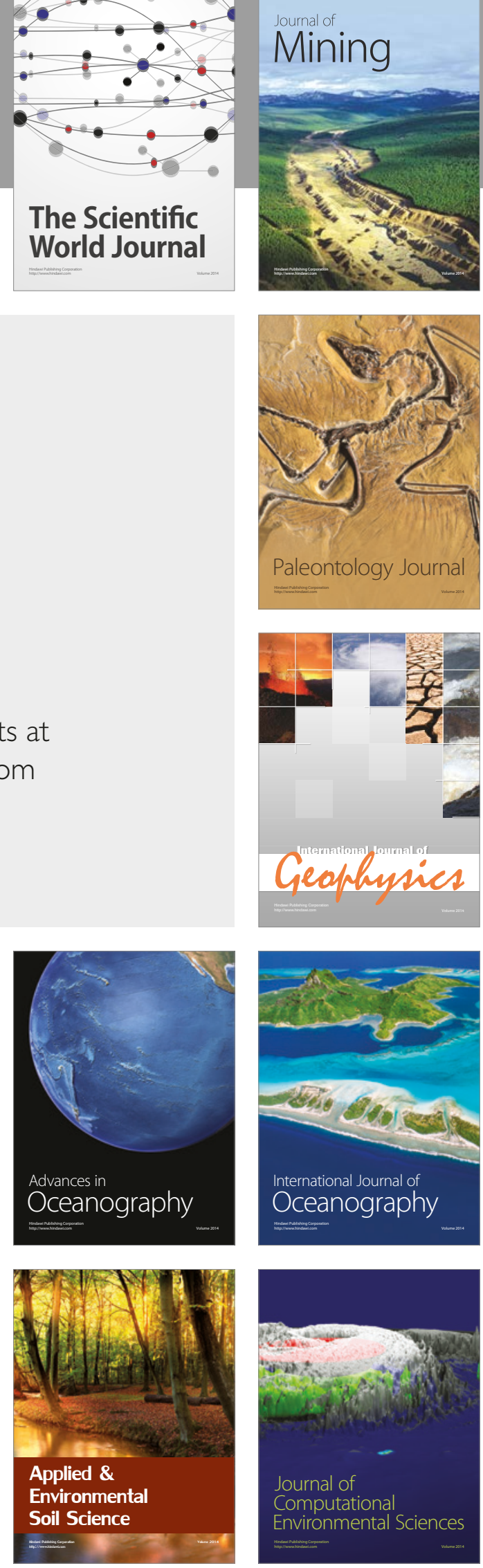